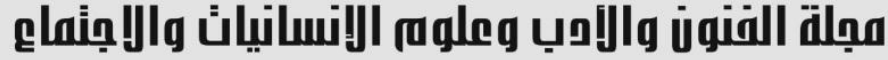

Journal of Arts, Literature, Humanities and Social Sciences www.jalhss.com

\section{الفن الثعبي (Pop Art) و إنعكاساته على تصميم الجدران في الفضاءات الداخلية}

\author{
هلوهس فارس سعدي \\ قسم الفنون التثكيلية ـ التصميم الأخلي ـ كلية فنون الجميلة ـ جامعة صلاح الدين- أربيل ـ كردستان العراق \\ hawasfaris@gmail.com الايميل \\ د.خالد عبدالوهاب سلطان \\ قسم الفنون التثكيلية - جامعة جيهان- دهوك ـ كردستان العراق \\ الايميل: drkhalid.art@gmail.com
}

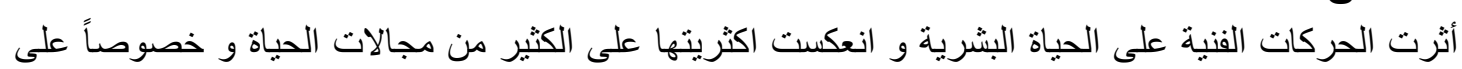

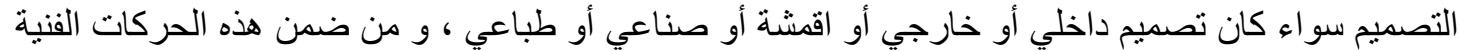

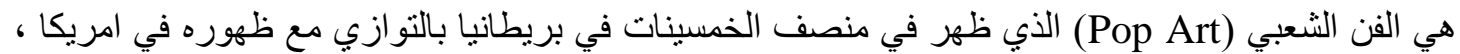

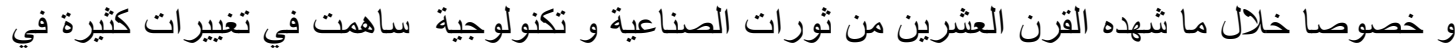

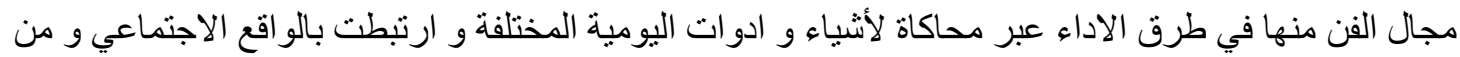

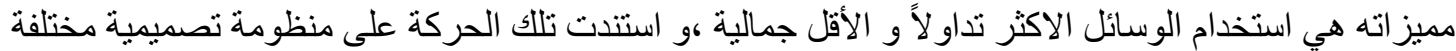

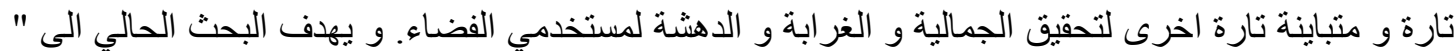
الكثف عن مفهوم البوب و انعكاساته على تصميم الجدران في الفضاءات التهات الداخلية"من خلال ماتناولته من الإطار المنهجي من مشكلة البحث و التي تحددت من خلال الإجابة على السؤال التالي (ماهو الفن الثعبي (Pop Art) و

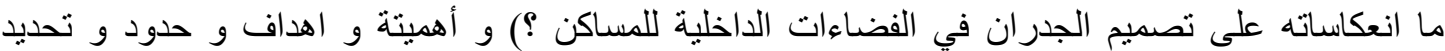

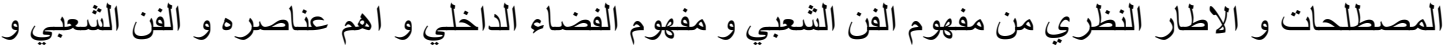

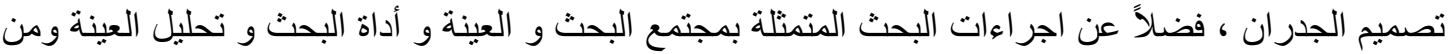

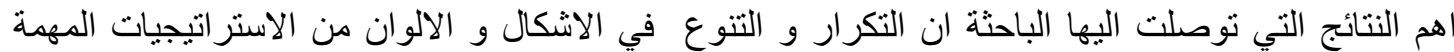

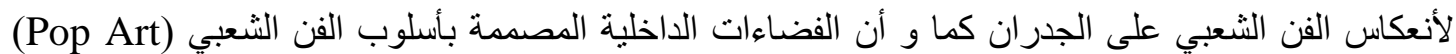

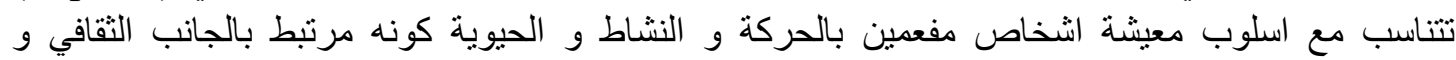
الاجتماعي و السياسي و الاقتصادي.

الكلمات المفتاحية: الفن الشعبي، تصميم الجدران، الفضاءات الداخلية. 


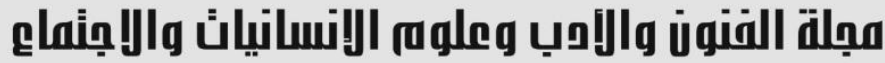 Journal of Arts, Literature, Humanities and Social Sciences www.jalhss.com \\ Volume (52) May 2020 العدد (52) مايو 2020 \\ Pop Art and Their Reflection on Walls Design in the Interior Spaces
}

\author{
Hawas Faris Saadi \\ Plastic Arts Department - Interior Design - College Of Fine Arts \\ Salahaddin University-Erbil- Iraqi Kurdistan Region \\ Email: hawasfaris@gmail.com
}

\author{
Dr. Khalid A. Sultan \\ Plastic Arts Department- Cihan University- Duhok- Iraqi Kurdistan Region \\ Email: drkhalid.art@gmail.com
}

\begin{abstract}
The artistic movements affected human life, and most of them were reflected in many areas of life, especially on design, whether it is interior or exterior design, fabrics, industrial or print, and among these artistic movements is the popular art (Pop Art) that appeared in the mid-fifties in Britain in parallel with its appearance in America, especially the crescent of the industrial and technological revolutions of the twentieth century that contributed to many changes, including in the methods of performance through simulation of different everyday things and tools and were linked to social reality and its advantages are the use of the most widely used and least aesthetic means, And that movement was based on who Sometimes different design anybody as long and mixed at other times to achieve the aesthetic and strange and surprising to users of space. And the current research aims to "reveal the concept of pop and its repercussions on the design of the walls in the interior spaces" through what it covered from the methodological framework of the research problem, which was determined by answering the following question (What is Pop Art) and what are its implications for the design of the walls In the interior spaces of the dwellings?) And its importance, goals, limits and defining terms and theoretical framework from the concept of folk art and the concept of interior space and its most important elements and folk art and wall design, in addition to the research procedures represented by the research and sample community and the research tool and analysis The sample and the findings of the researcher Repetition and diversity in shapes and colors are important strategies for reflection of folk art on the Also, the interior spaces designed in the style of Pop Art are compatible with the lifestyle of people who are full of movement, activity and vitality, as it is linked to the cultural, social and political aspect Economic.
\end{abstract}

Keywords: Pop Art, wall design, interior spaces. 


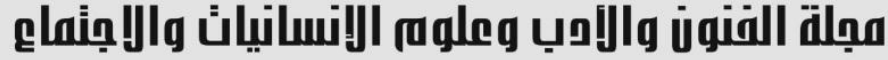

Journal of Arts, Literature, Humanities and Social Sciences www.jalhss.com

مشكلة البحث : شهر النصف الثاني من القرن العشرين متغير التهن ارتبطت بالحربين العالميتين الأولى و الثانية

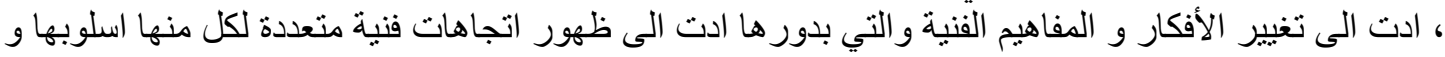

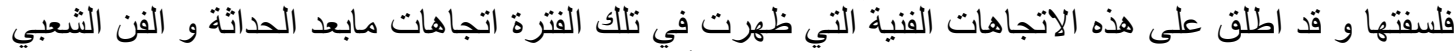

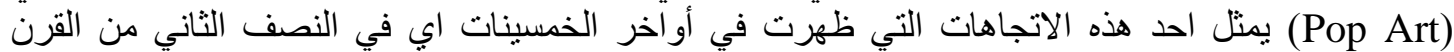

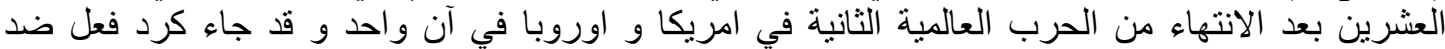

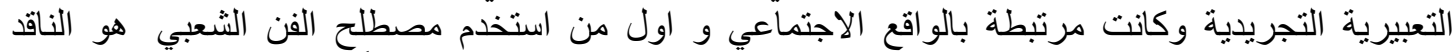

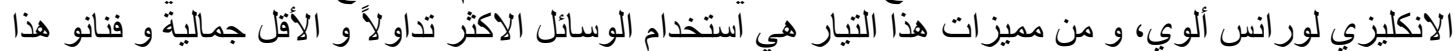

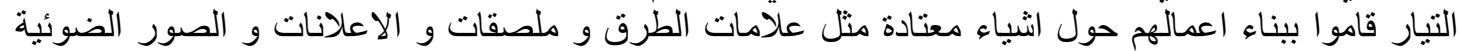

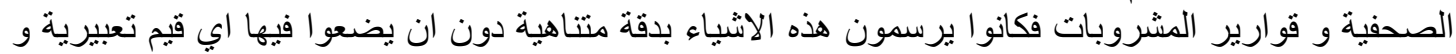

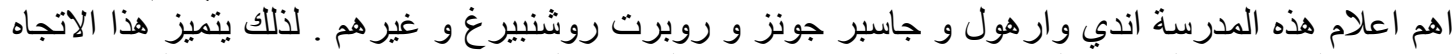

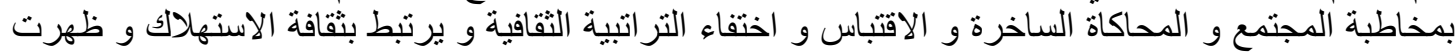
في هذا الاتجاه في مجال الفن و انعكست على مجالات عدة منها الاعمال النحتية و التصميم المباني و التصميم

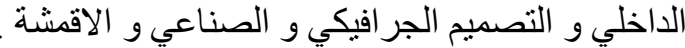

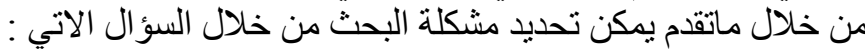
ماهو الفن الثعبي (Pop Art) و ما انعكاساته على تصميم الجدران في الفضاءات الداخلية للمساكن ؟

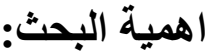

$$
\text { تتجسد اهمبة البحث الحالي في ما باتٔي : }
$$

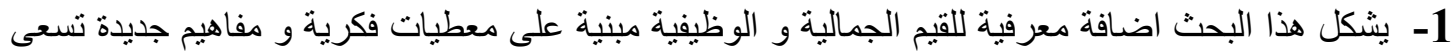
لتحقيق أفكار ابداعية للمختصين و العاملين في مجال التصميم الداخلي. 2- بساهم البحث في توسيع الثقافة الفنية و الجمالية لاى الطلاب الدارسين في الجامعات في مجال الفنون التثكيلية و الفنون التطبيقية (النصميم الداخلي).

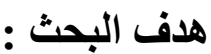

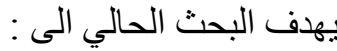
الكثف عن مفهوم اللفن الثنعبي و انعكاساته على تصميم الجدران في الفضاءات الداخلية للمساكن بشكل يتلائم مع حاجة مستخدميها. حدود البحث : حلثريكا 1. الددود الدوضو عية : انعكاس الفن الثعبي (Pop Art) على تصميم الجدران في الفضاءات الداخلية والذي يتحدد بالفضاءات السكن (المنزل).

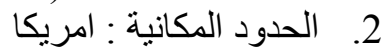
3. الحدود الزمانية : يتحدد البحث زمانياً في (2012-2019).

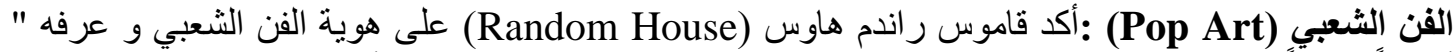

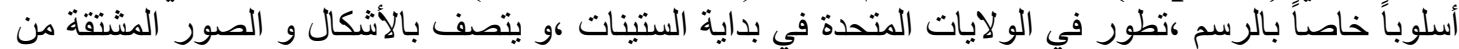

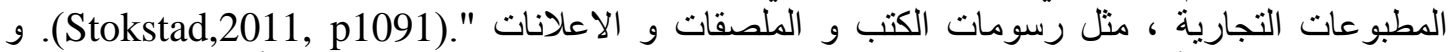

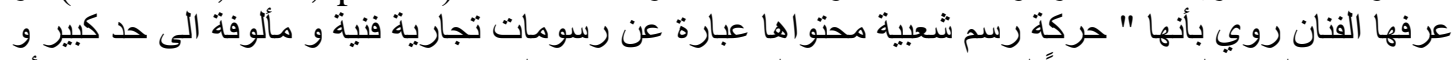

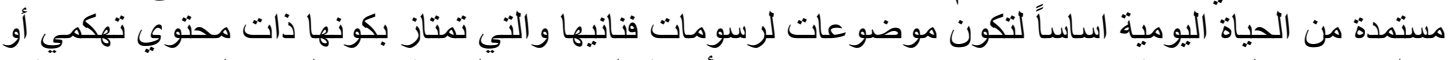

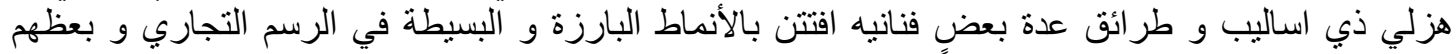

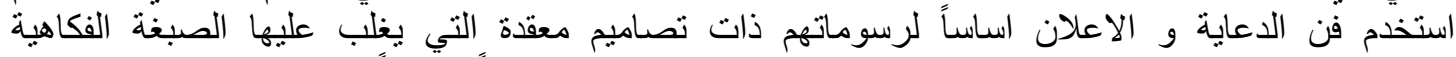

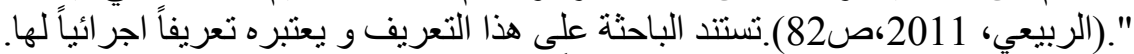

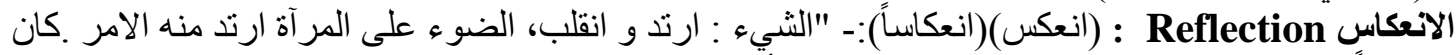
معكوساً".(محمود ،1997،ص185). عرفها الباحثة بأنها انتقال مفهوم الفن الشعبي و تجليه على سطح الجدران التهان 


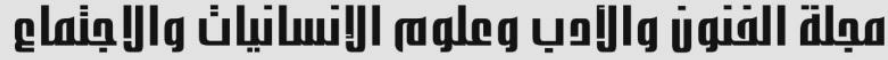

\section{Journal of Arts, Literature, Humanities and Social Sciences www.jalhss.com}

Volume (52) May 2020

العدد (52) مايو 2020

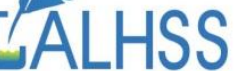

في صورة اثر و الناتج الذي يتركه على الجدار شكلباً و اسلوبياً و تقنياً محققاً بذلك اثراً جمالياً منسقاً مع الفضاء الداخلي وظيفياً و تعبيرياً.

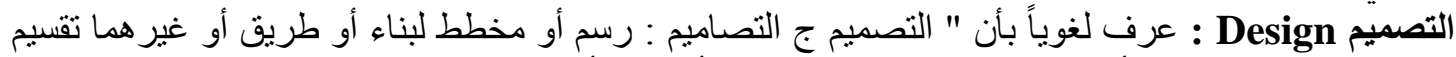

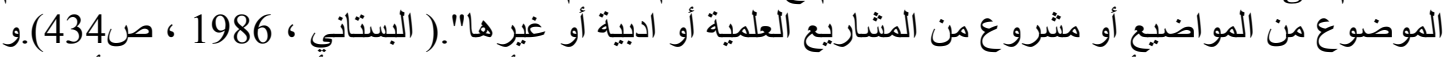

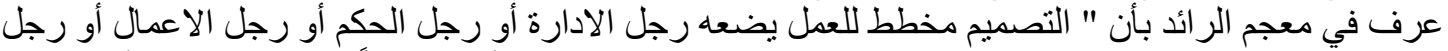

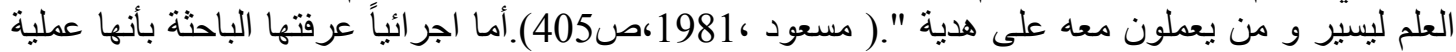

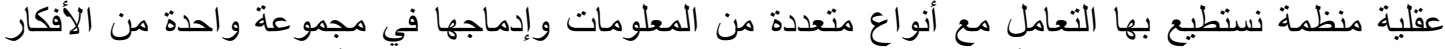

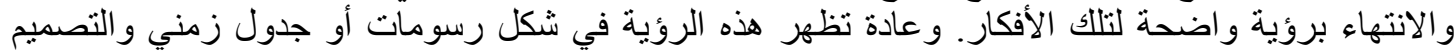
يتضمن الطريقة والمنتج في نفس الوقته

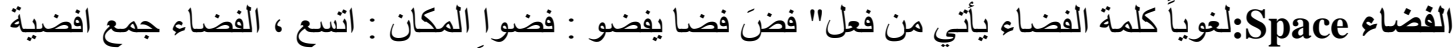

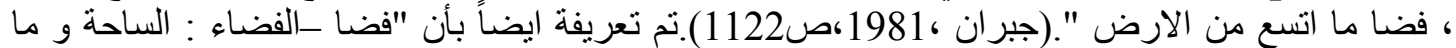

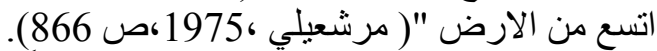

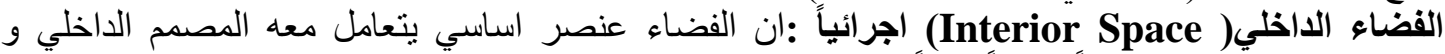
الفضاء بشكل عام يعد فراغاً (مكاناً خالياً) ، و بمجرد وضاً ونع عنصر الفاء داخله تحقق لنا علاقات بصرية متعددة بين الفين

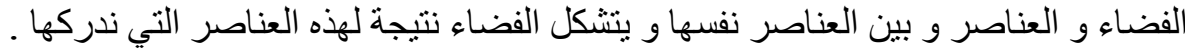

\section{الفصل الثاني:الاطار النظري}

أولاً : مفهوم الفن الشعبي (Pop Art): ظهر الفن الشعبي نتيجة لفقدان الانسان الاتصال بالطبيعة وذلك

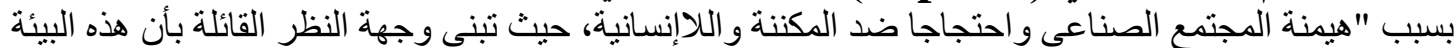

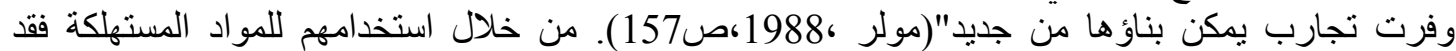

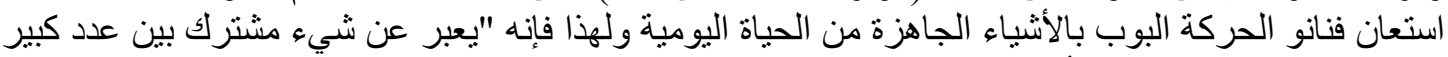

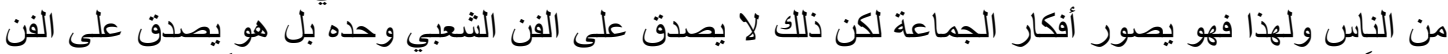

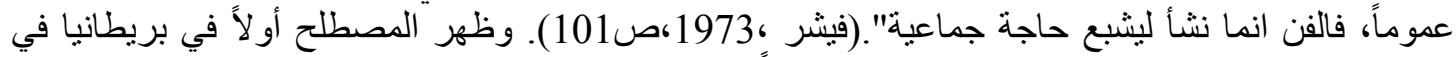

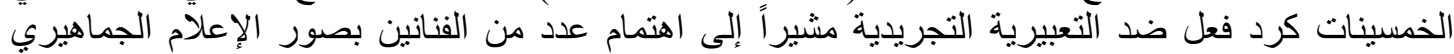

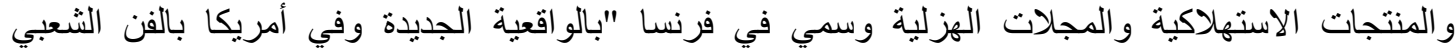

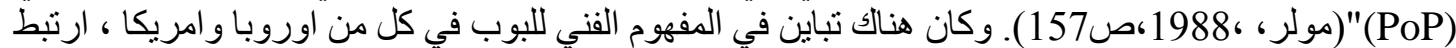

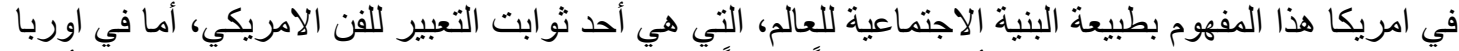

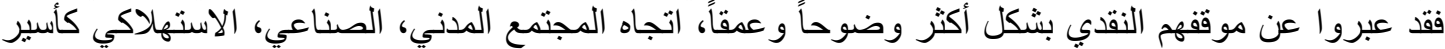

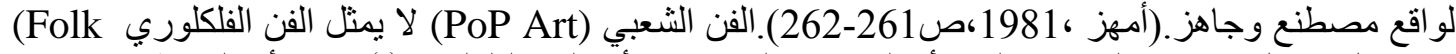

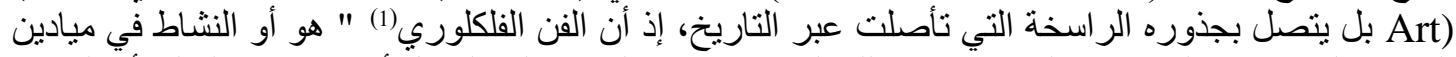

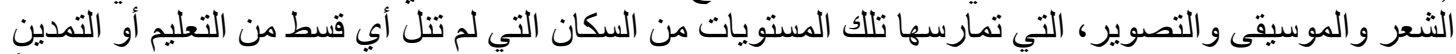

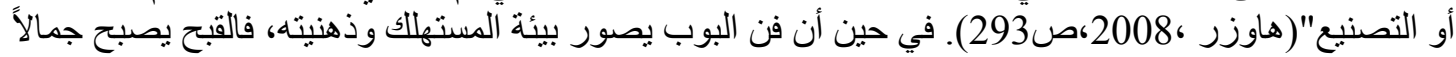

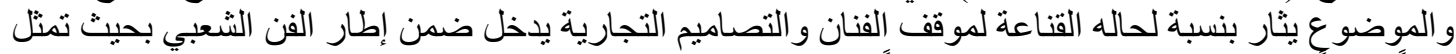

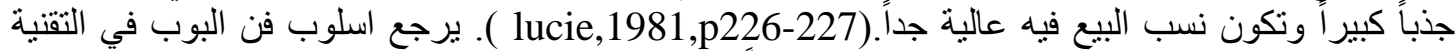

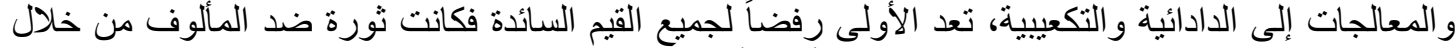

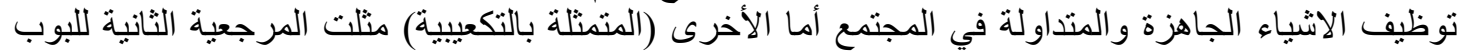

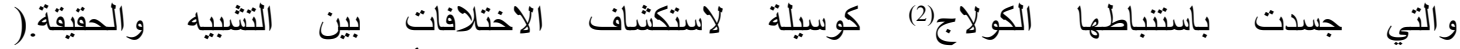

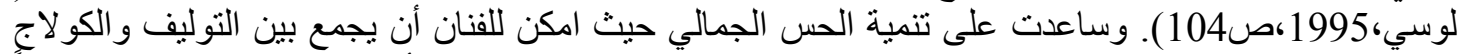

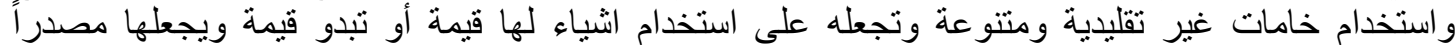

لإحساسه بالجمال وتعبيره.(Compton ,1970,p6). 


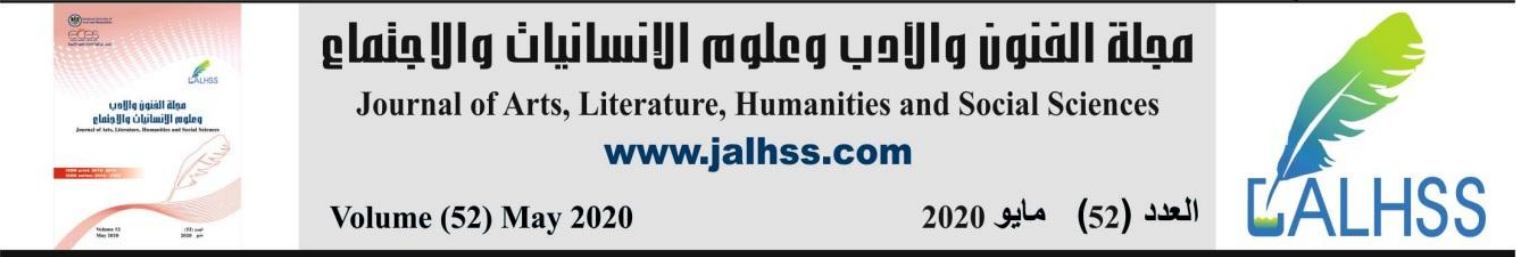

الى جانب استخدام الكولاج استخدم التصوير الفوتوغر افي كجانب مكمل بشكل خاص في اعلى اعلانات الدعاية

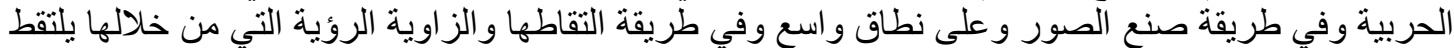

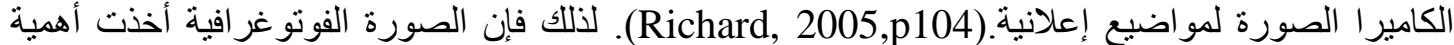

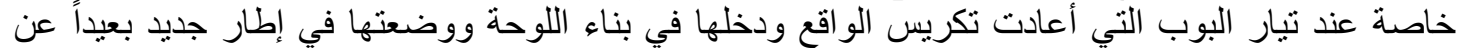

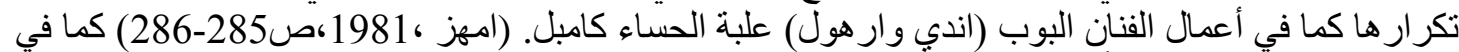

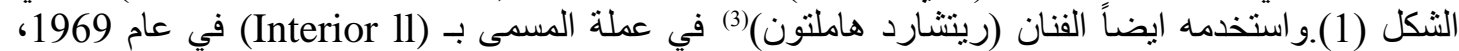

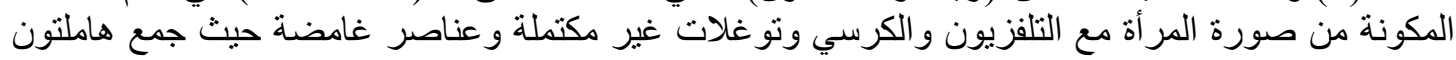

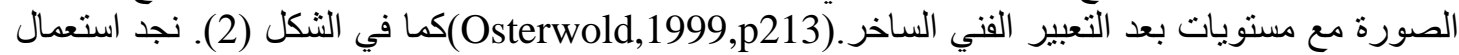

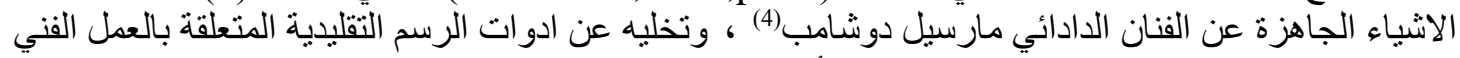

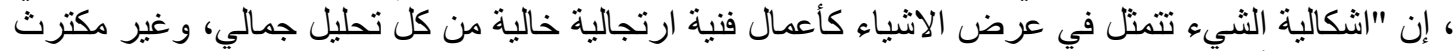

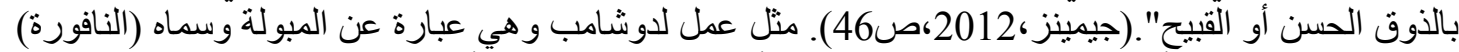

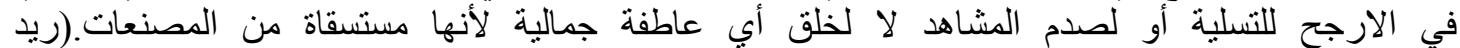

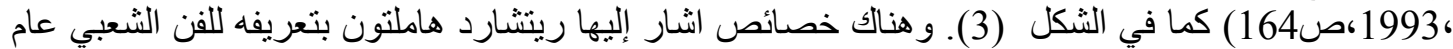

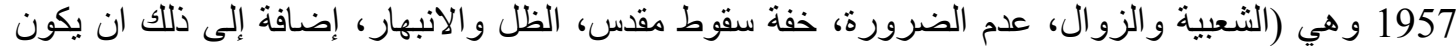

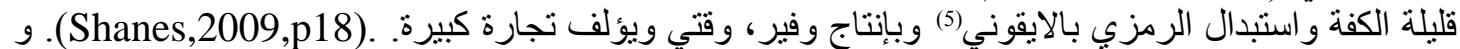

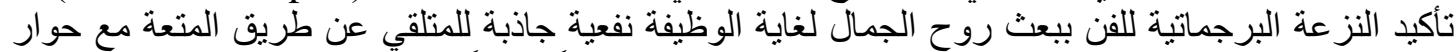

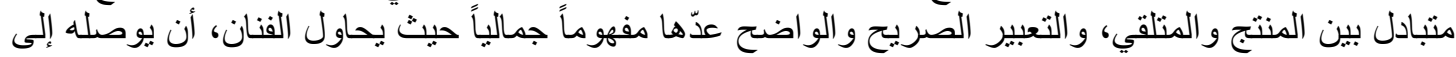

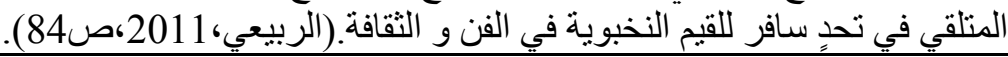
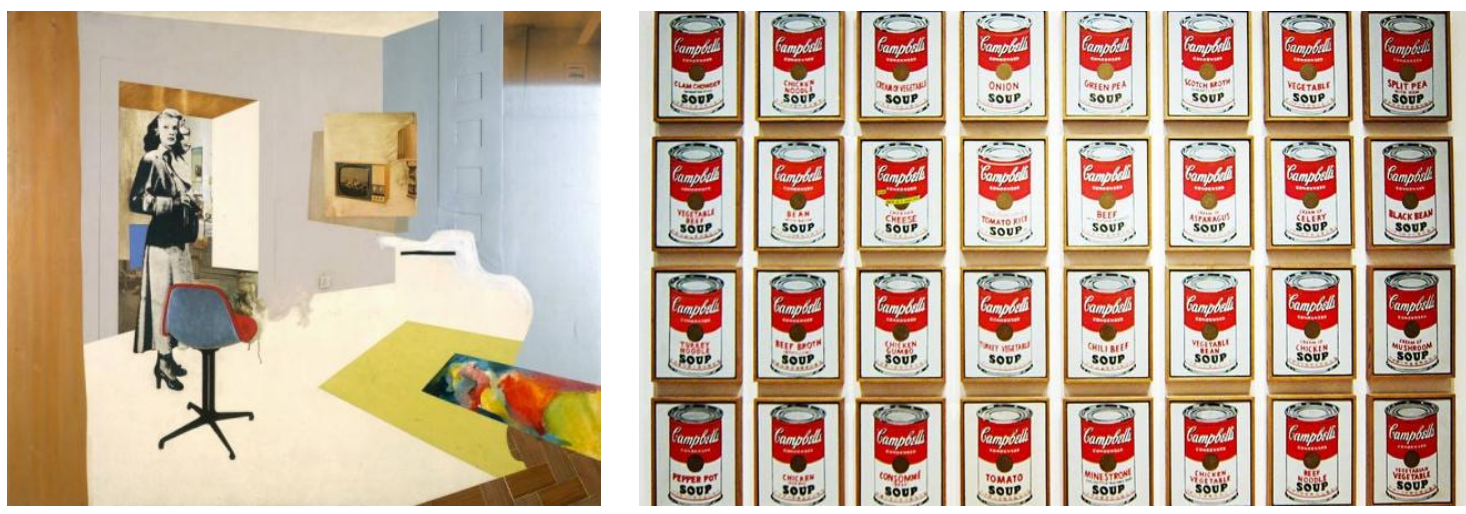

الثكل (2) علبة حساء كامبل للفنان (اندي و ارهول) الثكل (2) (Interior 11) للفنان ريتشارد هاملتون

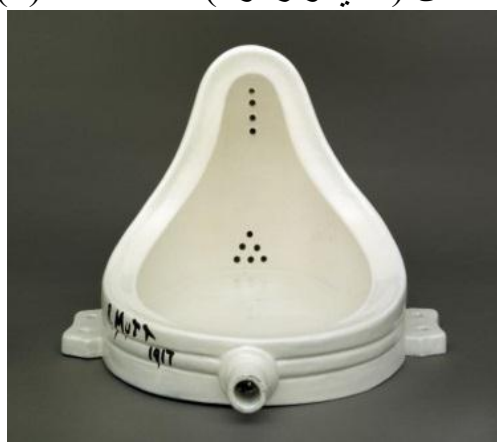

الثكل (3) عمل (المبولة ) للفنان مارسيل دوشامب

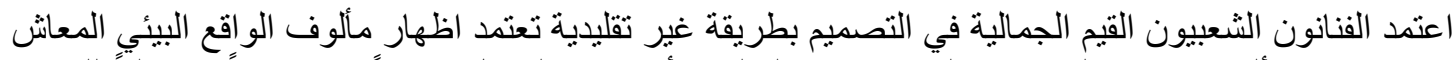

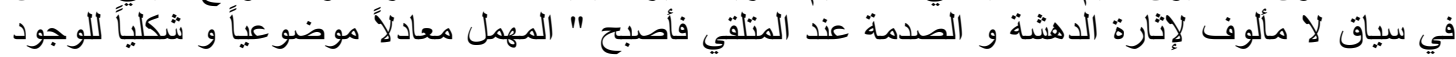




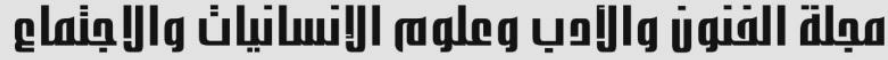

Journal of Arts, Literature, Humanities and Social Sciences www.jalhss.com

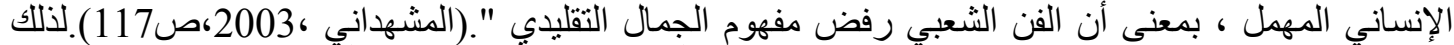

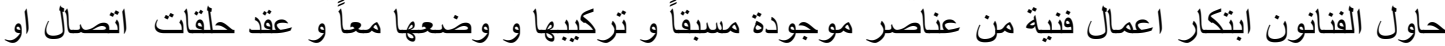

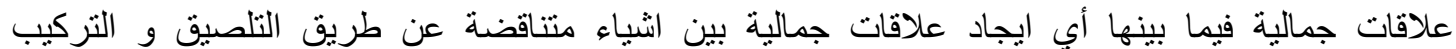
(Collage)

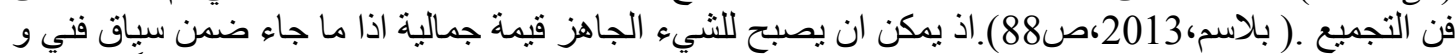

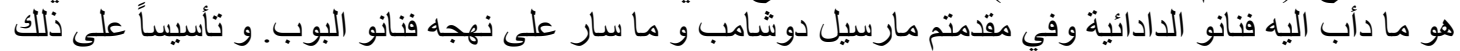

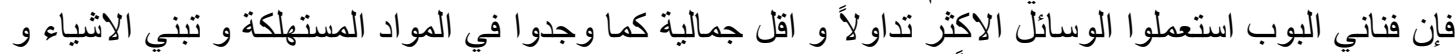
الرموز التي يتعامل معها الانسان يومياً لها قيمة جمالية تميز التهائ عملهم الفني ـ (Kries,2013,p35).

ثانياً :مفهوم الفضاء الداخلي

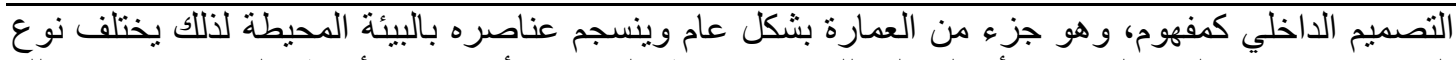

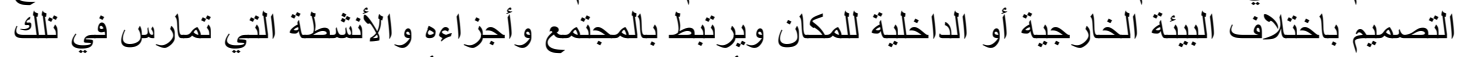

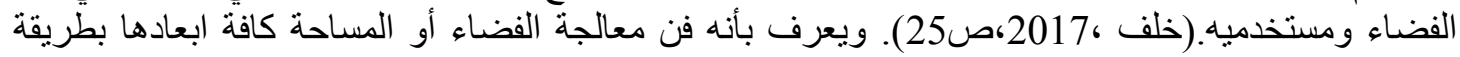

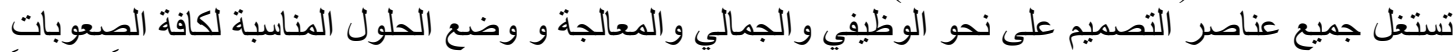

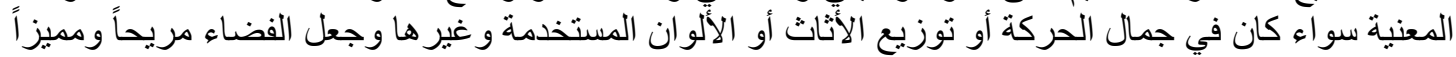

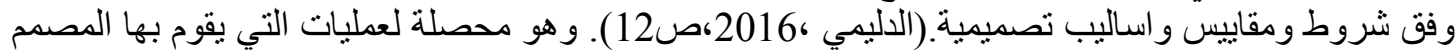

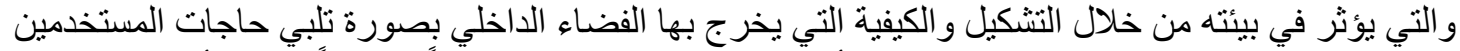

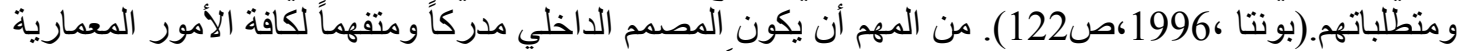

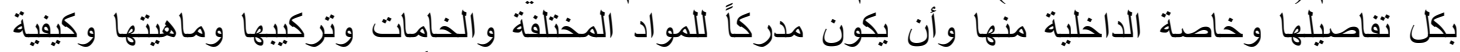

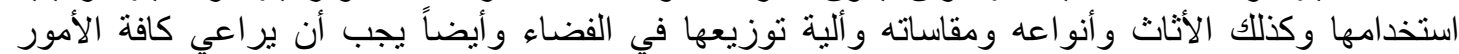

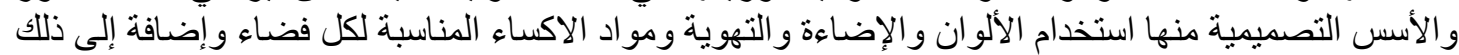

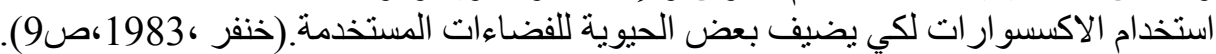

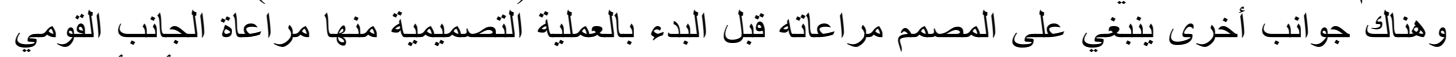

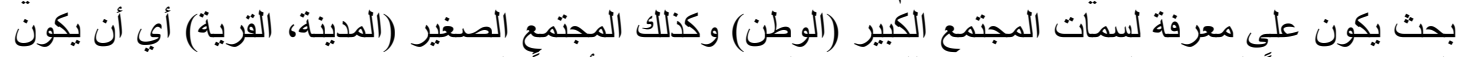

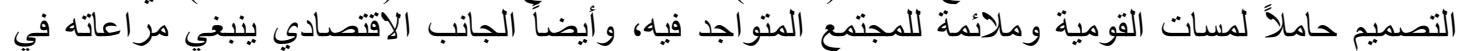

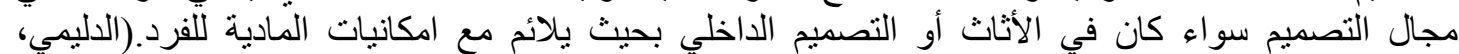

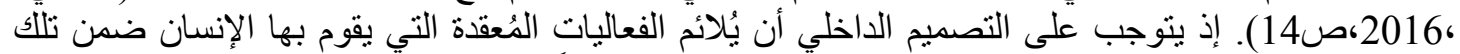

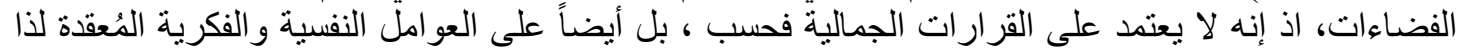

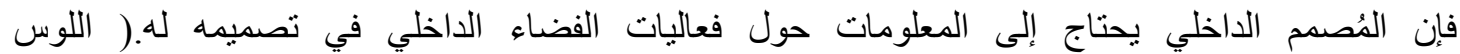
(16) 2000،

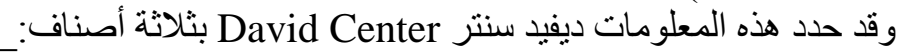

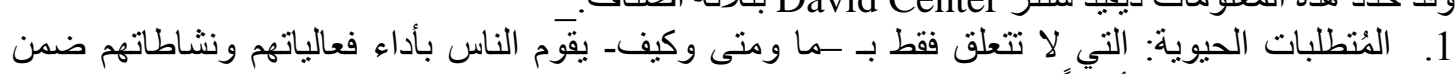

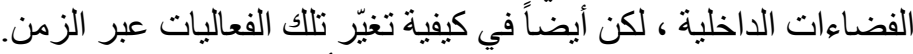

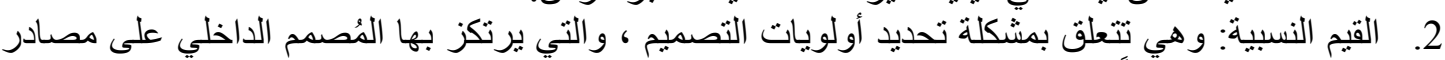

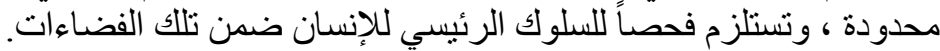

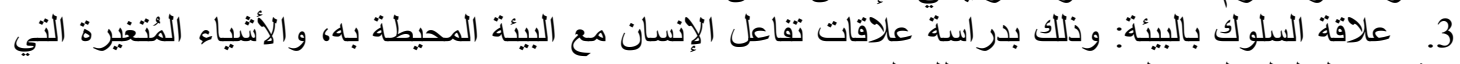
تؤثر في السلوك الدقيق للإنسان ضمن تلأك الفضاءات. Malnar,1992,p.21 ).

ثالثاً :عناصر تصميم الفضاء الأاخلي : و التي تنقسم الى (العناصر البصرية ، العناصر المحددة، العناصر الانتقالية ، العناصر التأثنيثية) :

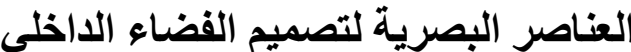

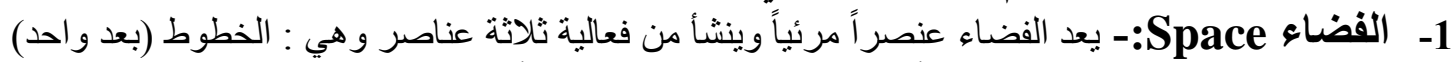

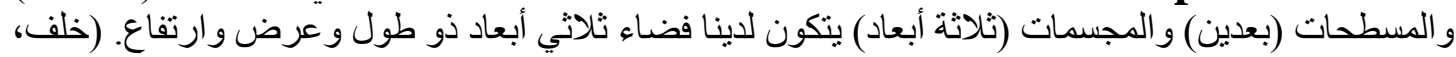




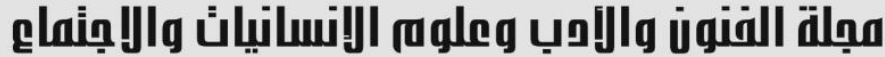

Journal of Arts, Literature, Humanities and Social Sciences www.jalhss.com

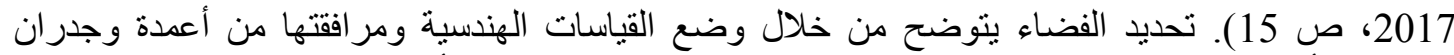

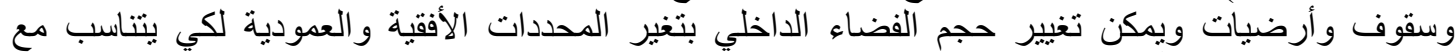

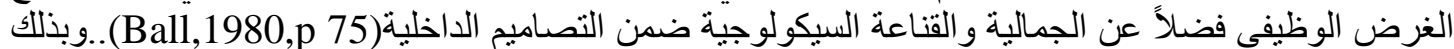

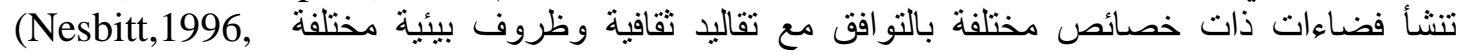
(و.p415)

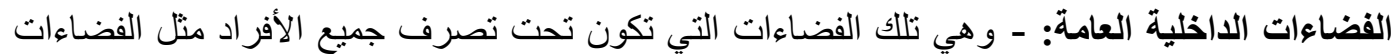

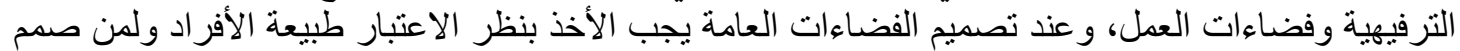
الفضاء و الغرض الذي أنشأ من أجله. (Fiedman, 1979, p 106).

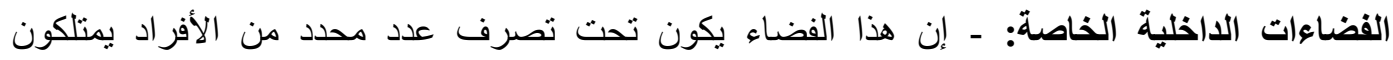

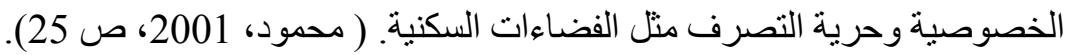

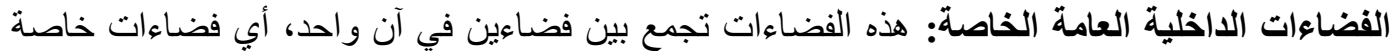

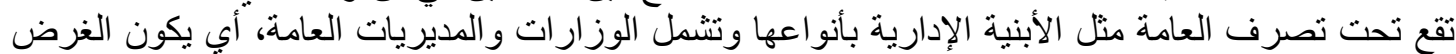

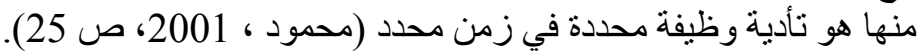
2 الرابط لنقطتين، فالنقطتان تكون محور أ، و المحور في الفضاء الداخلي يمكن إعداده الوسيلة التنظيمية لأشكال

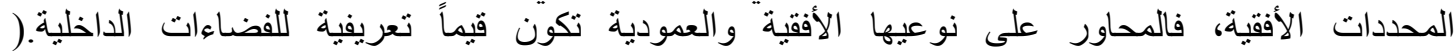

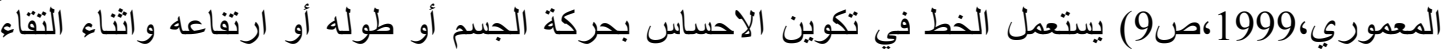

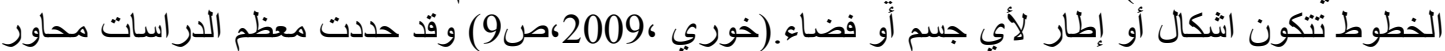

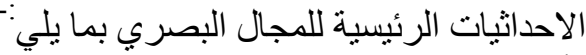

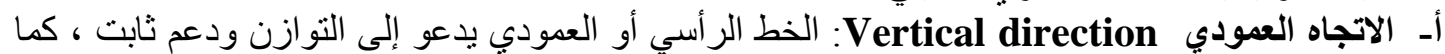

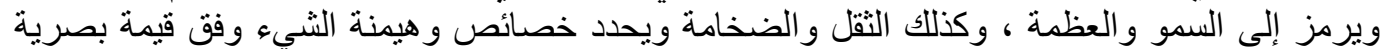
واستخدام الخطوط العمودية في التصميم في صورة متكررة يزيد الاحساس بالقوة والصياء ولصلابة لعلاقات

$$
\text { الخطوط.(Rodolf ,1974,p36-37). }
$$

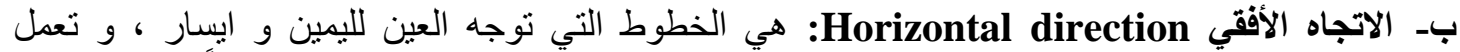

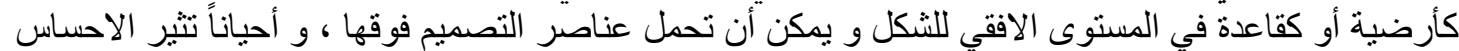

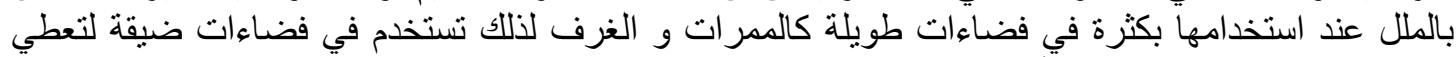

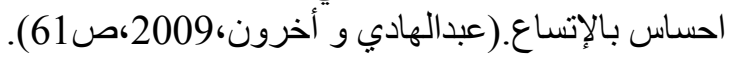

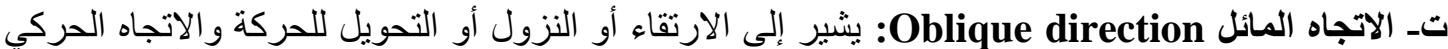

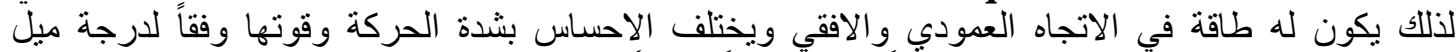

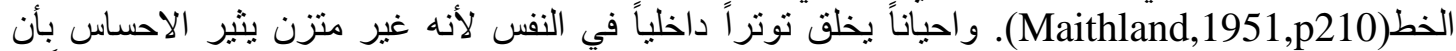

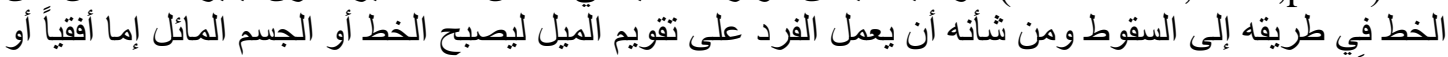

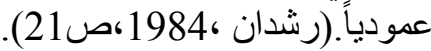

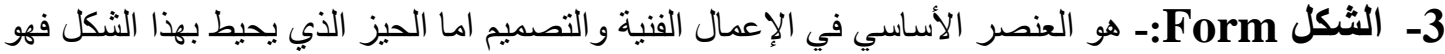

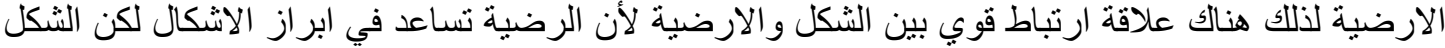

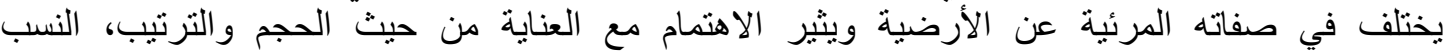

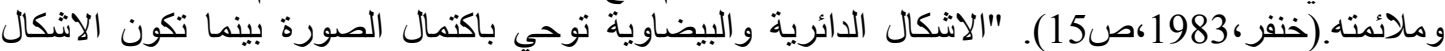

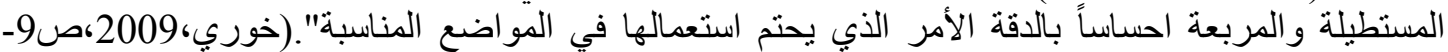

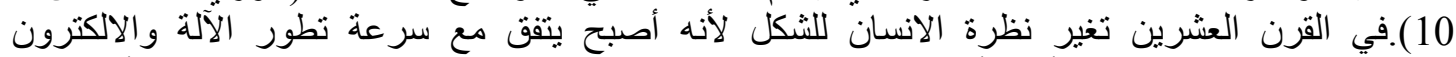

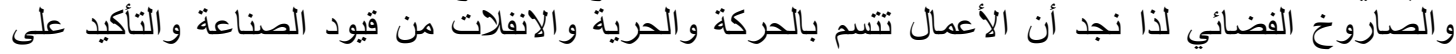

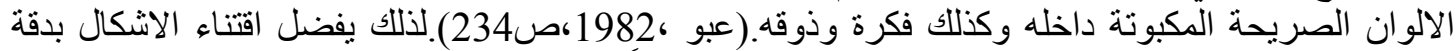

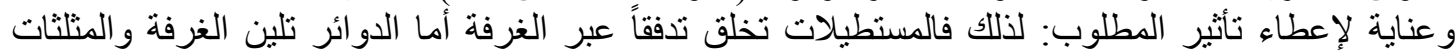




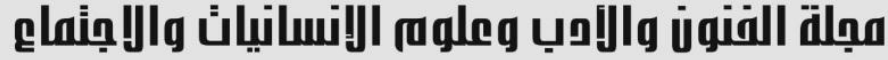

\author{
Journal of Arts, Literature, Humanities and Social Sciences
} www.jalhss.com

تعطي الثعور بالاستقرار في الغرفة، لذلك فهم الخطوط والفضاء بستجلب بطبيعته شكل ايجابي إلى الى الفي

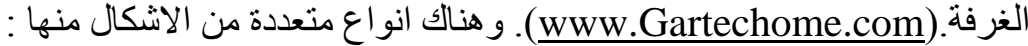
• الاشكال الهندسية: المتلث ، المربع، المسنطيل، الدائرة ،... الخ، فهي نتاج لأشكال طبيعية ،وهي هندسية

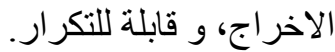

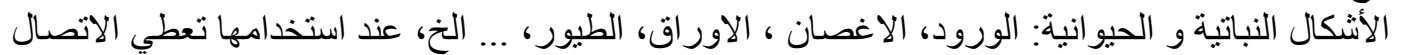

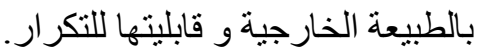
• • اشكال الأشخاص: تأكيد على نوع الجنس أو إعطاء هيئات تأريخية للتأكيد عليها. • الثكال الكتابية :يترتب بطريقة هندسة أو نباتية أو حيو النية أو اشخاص أناص أو تكون مجردة عن المضمون

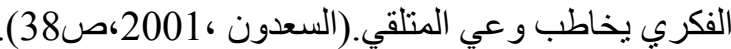

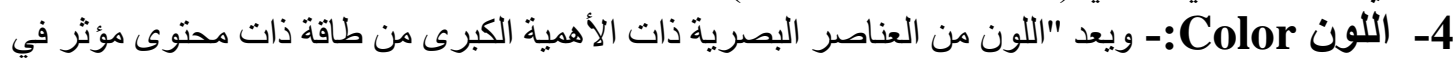

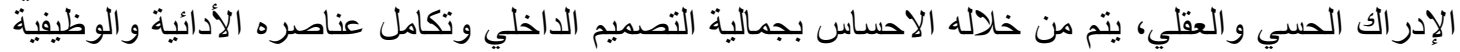

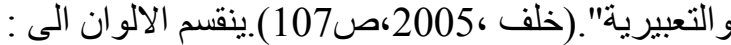

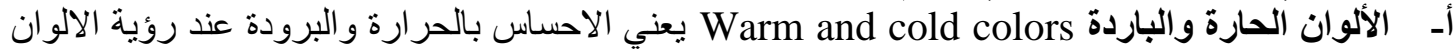

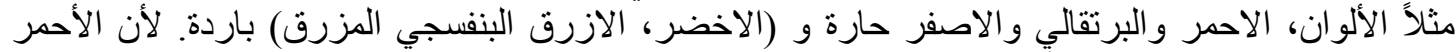

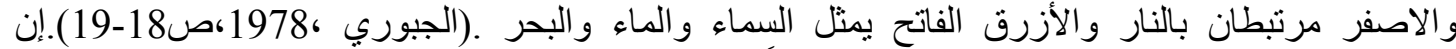

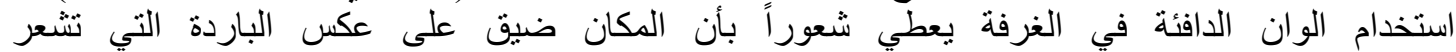

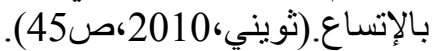

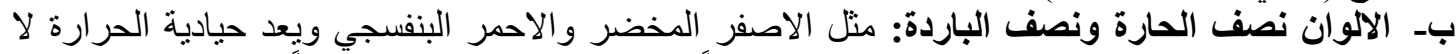

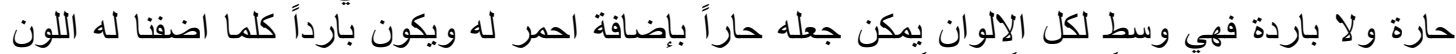

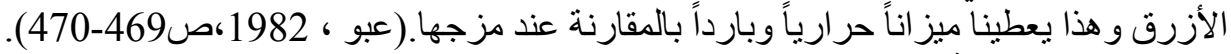

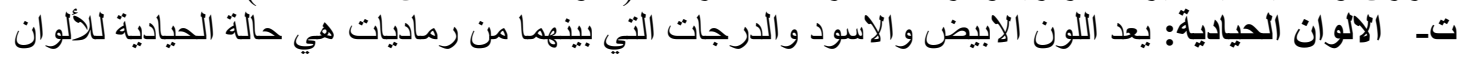

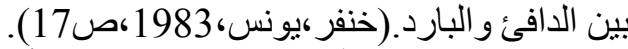

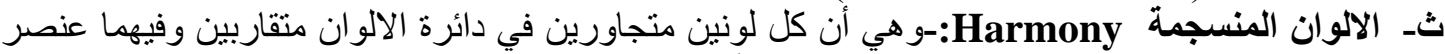

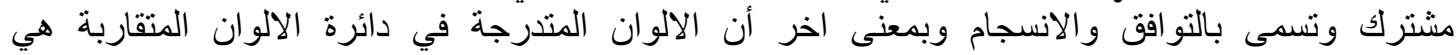

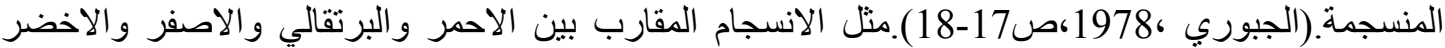

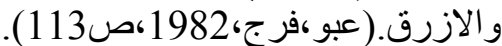

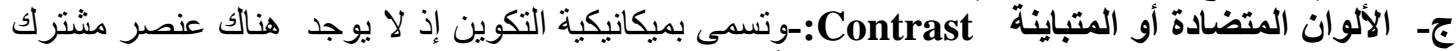

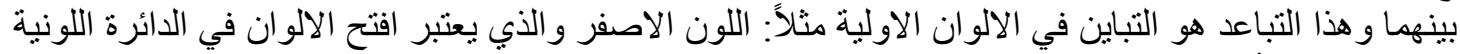

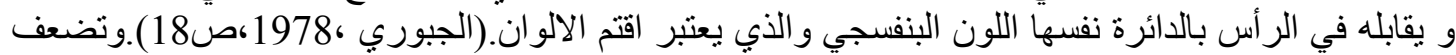

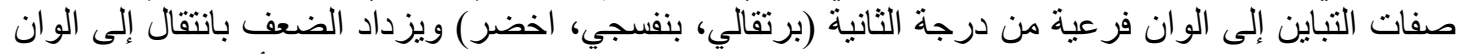

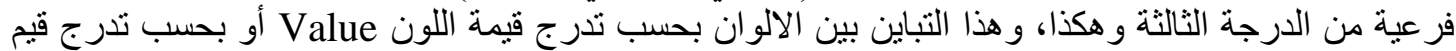

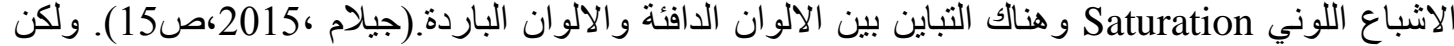

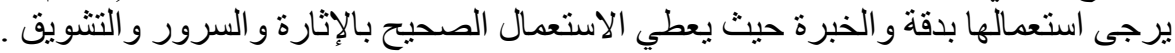

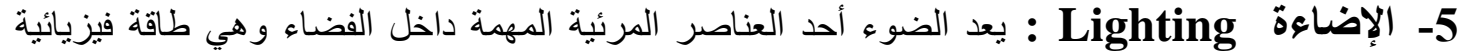

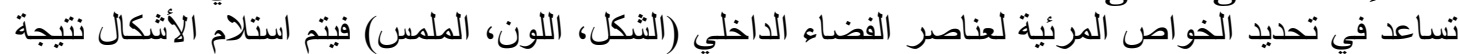

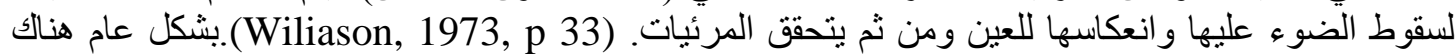
مصدران للإضاءة والذي يستعمل في الفضاءات الداخلية أولهما الاضاءة الطبيعية (Natural Lighting) مصدر ها الثمس والقمر، وثانيهما الإضاءة الصناعية (Artificial Lighting) ينبعث بأنشكال مختلفة منها

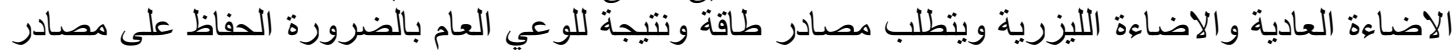

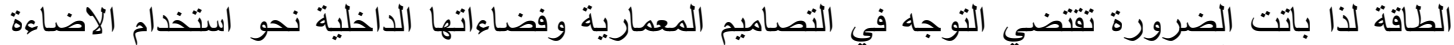

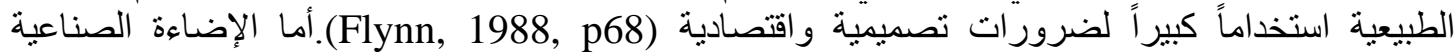
تنظيمها وتوزيعها في الفضاءات الداخلية العامة و الخاصة غالباً يكون في السقف و الجدران وتككون ضمن الإن التهن 


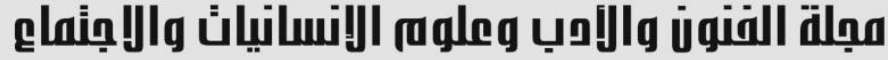

\author{
Journal of Arts, Literature, Humanities and Social Sciences \\ www.jalhss.com \\ Volume (52) May 2020 \\ العدد (52) مايو 2020
}

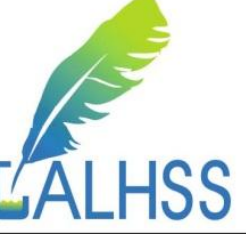

أ_الاضاءة العامة:- توضع بطريقة متجانسة ومتشتتة على عموم الفضاء ويمكن أن يكون مباشرة أو غير مباشرة،

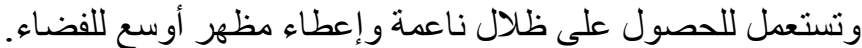

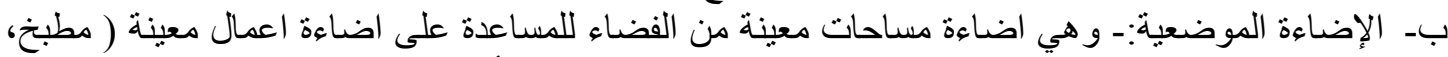

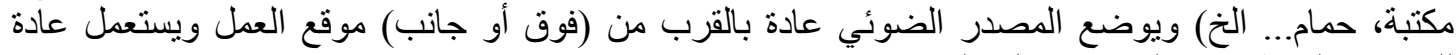
ك-للتوجيه و السيطرة في الفضاءات الداخلية (32 - Gary, 1995, p 30 (G).

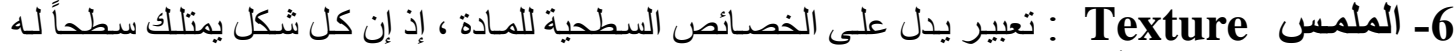

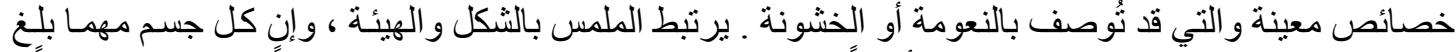

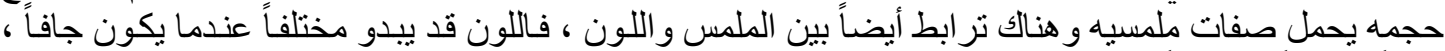

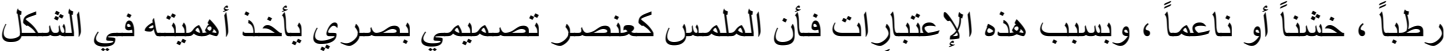

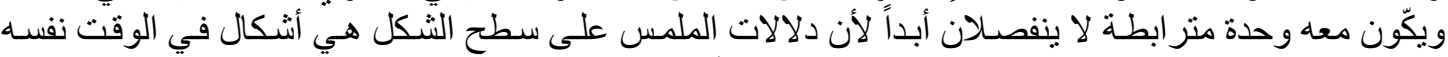

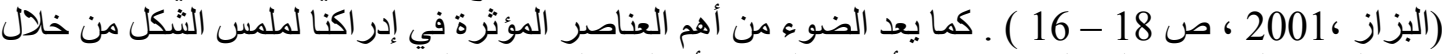

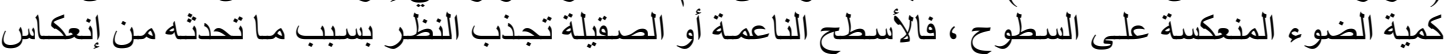
عالي للضوء ، في حين إن السطوح الخشنة يكون الإنعكاس فيها بإسلوب وكمية إضـاءة مختلفة ( رياض، 1973

(

\section{العناصر المحددة للفضاء الاخلي: -}

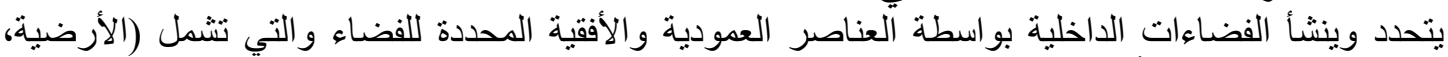

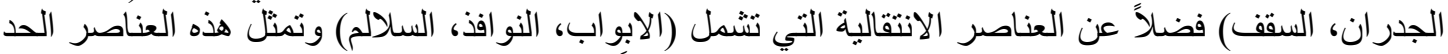

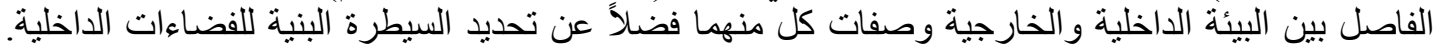

(Ching, 1987, P13)

1- الأرضية Floor: و هي سطوح منبسطة التي توفر القاعدة الاساسية للفضاء الداخلي و عليها يتم التحرك

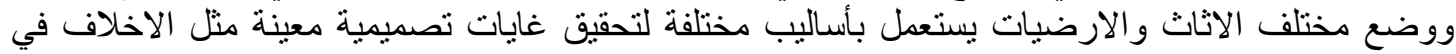

مستو يات الارضية وكذللك طبيعة الالوان و المو اد و الملمس. (Krier, 1988, p33).

2- الجدران: - The Walls: ويسمى بالمحددات العمودية وهي من العناصر المهوة التي تشكل وتعرف

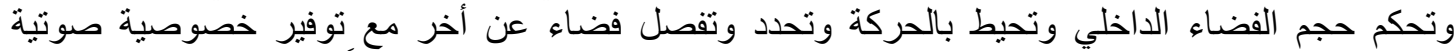

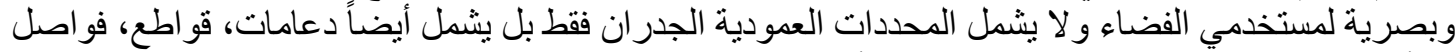

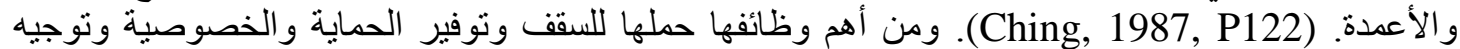
حركة الانسان واحتواء فعالياته المختلفة وتحديد ميزة الفضاء الداخلي وطبيعته "فالجدران تحان ولحدد العلاقات

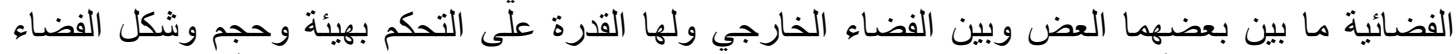
ويمكن ان نتلاعب أو نغير من منظوماته التناسبية باستخدام مواد إنهائية متعددة الأشكال والهينة

(Friedman, 1976, p23).

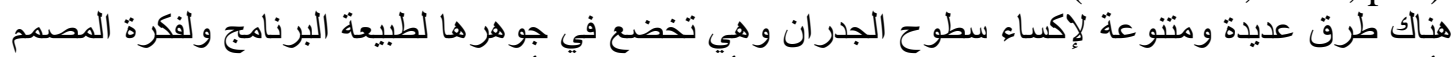

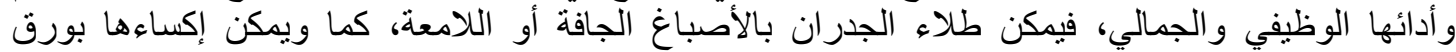

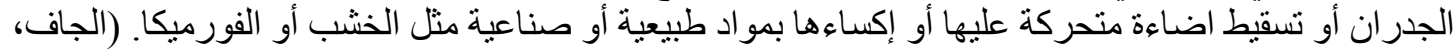

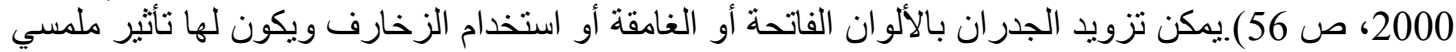

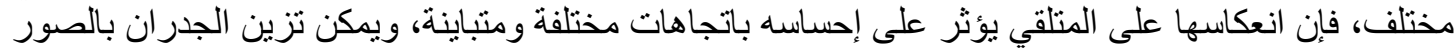

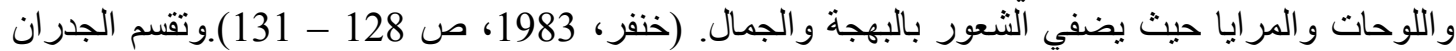

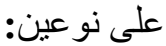

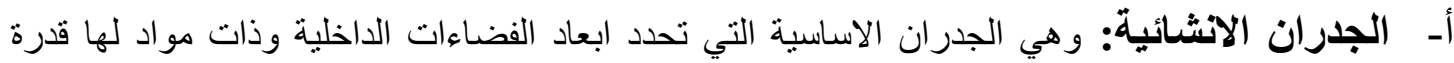

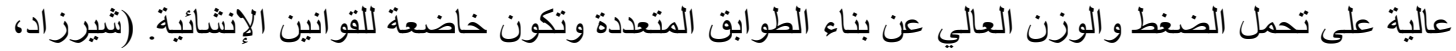

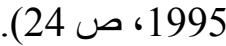
بـ الجدران الثانوية: - وهي جدران غير حاملة للأثقال تستخدم للفصل بين الفضاءات وتتميز بالمرونة

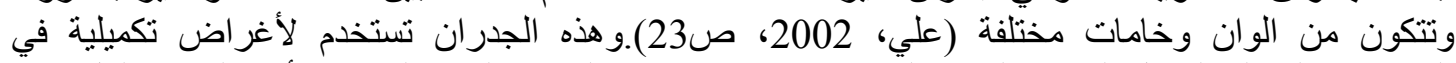
الفضاءات الداخلية لفصل الفضاء الواحد إلى عدة فضاءات ضدمن الفضاء الواحد لغدران لغرض تأدية الوظيفة لكل فرد، 


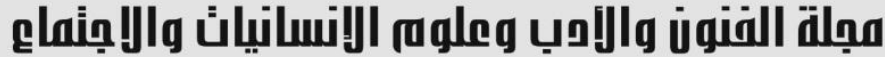

Journal of Arts, Literature, Humanities and Social Sciences www.jalhss.com

Volume (52) May 2020

العدد (52) مايو 2020

كالمكاتب أو التي تستخدم لتزين في المطاعم، البيوت، المستشفيات، غرف فنادق إذا كانت هذه الجدران الإن منحنية

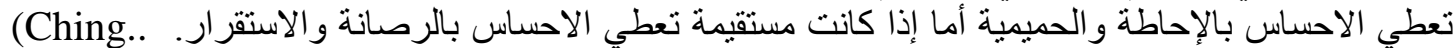
.1987, p180)

3- السقوف Ceiling: -و هي المحدد الأفقي الموازي لأرضية الفضاء الداخلي وتحديد بعده العمودي ويعد

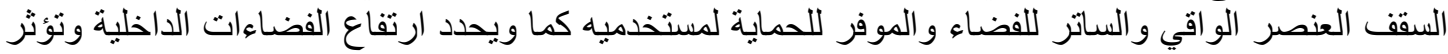

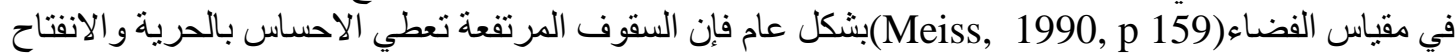
و السقوف المنخفضة تؤكد الانغلاق. (Ching, 1987, p 198).

\section{Transitional Elements العناصر الانتقالية:}

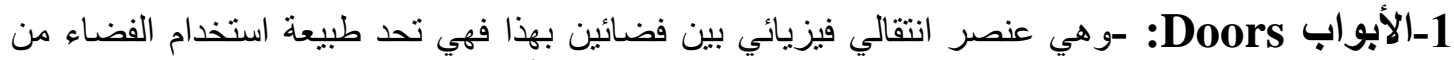

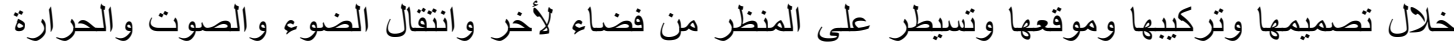

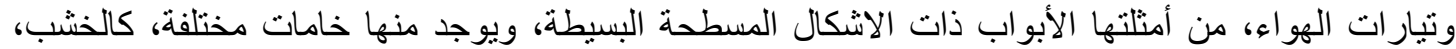
الزجاج، الالمنيوم... و غير ها. (خلف ، 2005، ص الأب 98).وأن الثكل وحجم وموقع الباب يساعد في تعريف طبيعة

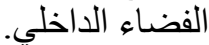

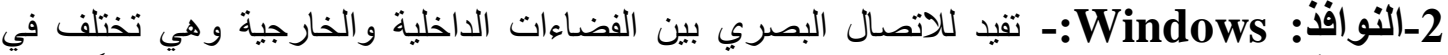

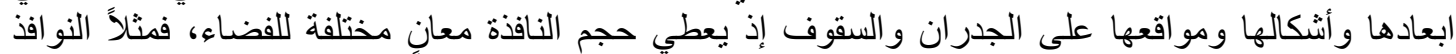

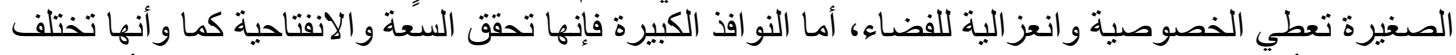

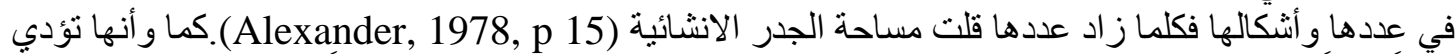
دور اً مهماً في توفير الضوء و التهوية الطبيعية بالإضافة إلى التأثير الجمالي وتؤثر أيضاً في طريقة نوزيع الأثاث

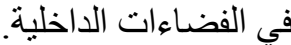

3-السلالم Stairs:- تعد السلالم إحدى وسائل الانتقال بين المستويات العمودية المختلفة ضمن المبنى ككل

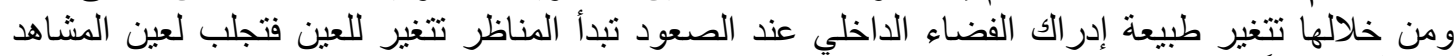

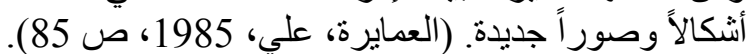

• العناصر التأثيثية Furnish Elements:-العناصر التأثنية يعد من العناصر المهمة في تصميم الفضاءات الداخلية وتتثمل (الأثاث والمكملات) وهي إحدى وسائل التعبير بين الفضاء الفياء الداخلي ومستخدميه فتشكها ولونها وملمسها وطر از ها كلها عو امل تسهم في تعزيز الفضاء الفاء الداخلي و إعطاءه معنى وصفينة مميزة

.(Ching, 1979, P240)

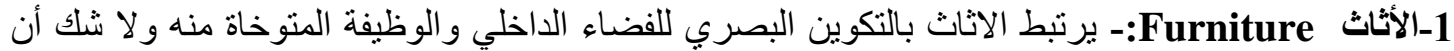

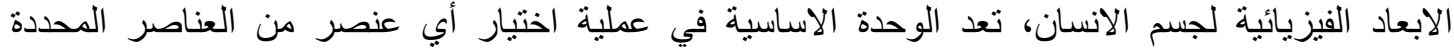

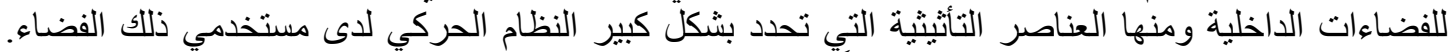

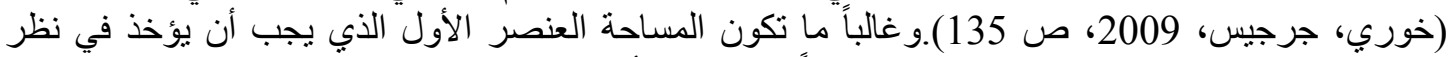

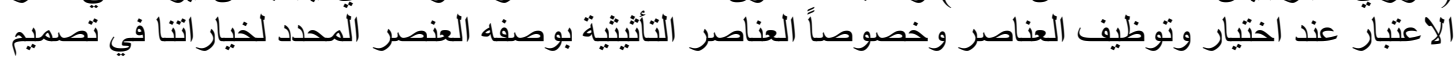

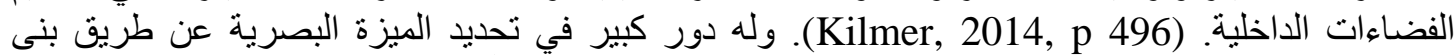

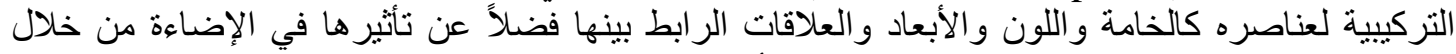
معامل الامتصاص و الانعكاس حسب طبيعة سطوح الأثاث. (Ball , 1980, p 88).

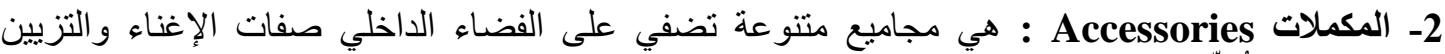

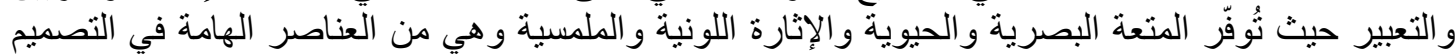

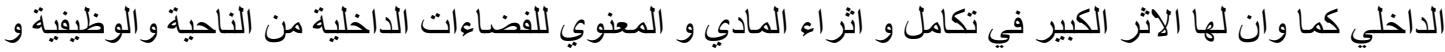




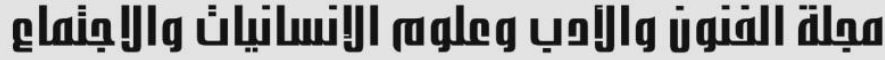

\author{
Journal of Arts, Literature, Humanities and Social Sciences \\ www.jalhss.com \\ Volume (52) May 2020 \\ العدد (52) مايو 2020
}

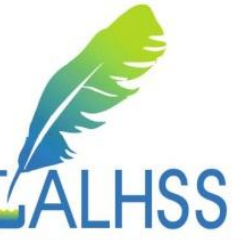

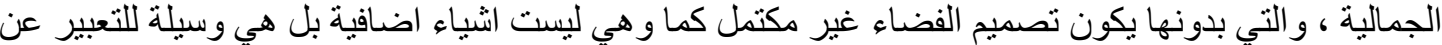

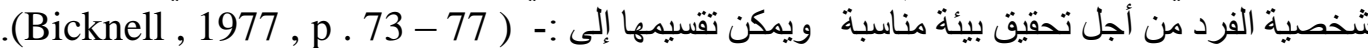

أ- المكملات النفعية Benefitail Accessories : وتثمل الستائر و الاواني الزجاجية و الخزفية ادوات المطبخ و الاجهزة الالكترونية و الكهربائية و الساعات و غير ها التي تستخدم في الفضاءات التئ الداخلية وتتسجم مع

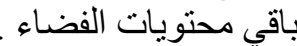
بـ المكملات التزينية Accessories Decorational : تعطي البهجة و الحيوية للفضاءات الفياء الداخلية وتقلل

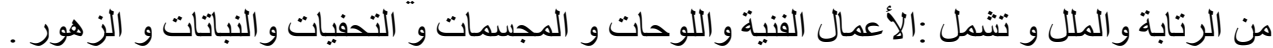

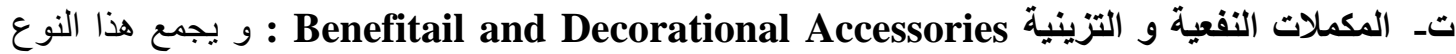

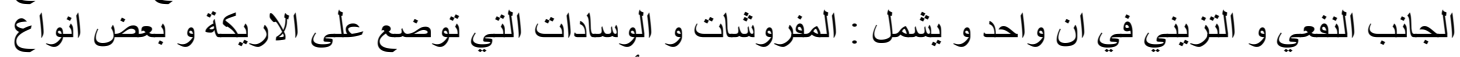

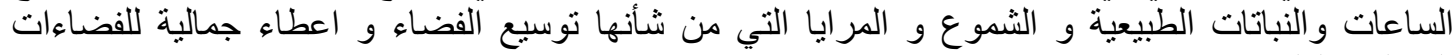
الداخلية.(الدليمي ،2016، صالنيات 287-300).

\section{العلاقات التكوينية لعناصر الفضاء الداخلي}

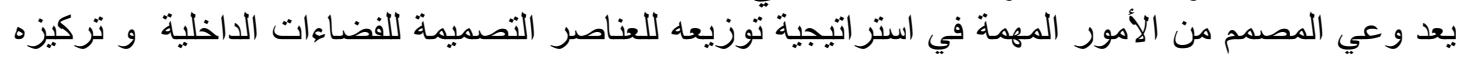

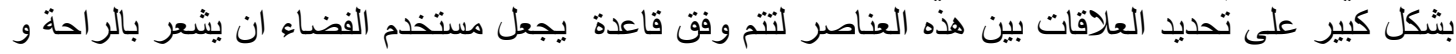

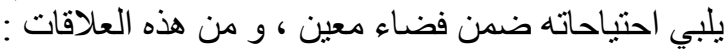

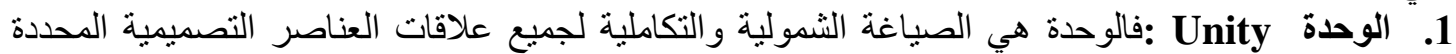

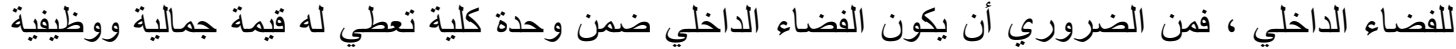
يساهم كل عنصر في التأثير الفني والحسي مما يكسبه معنى منسجم بعضه مع البعض الآخر ـ ـ ( شيرزاد ،1985

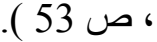

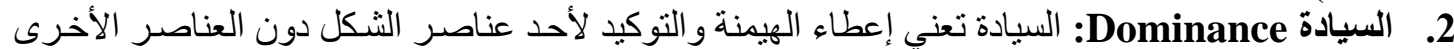

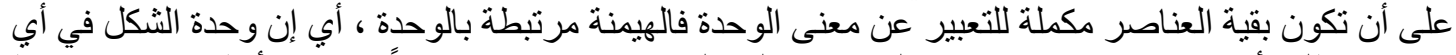

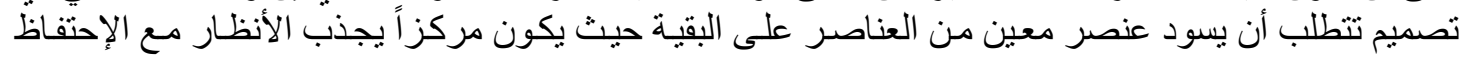

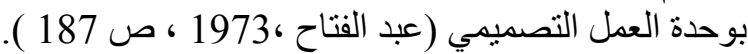

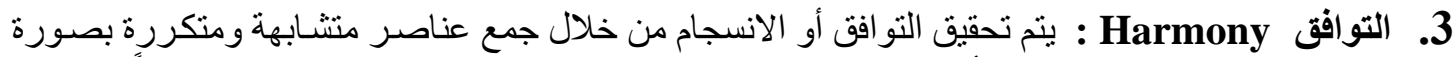

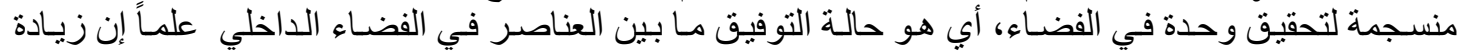

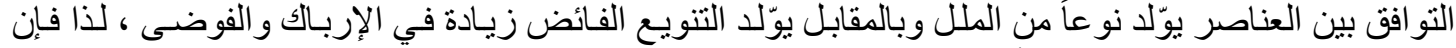

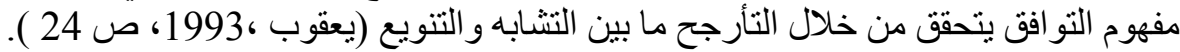

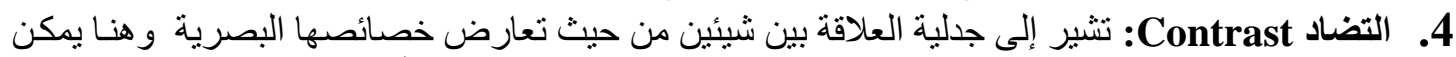

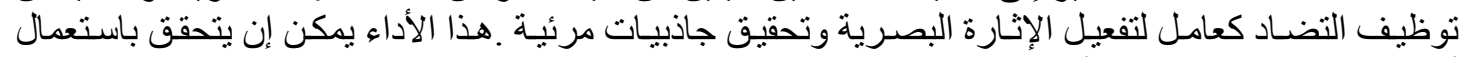

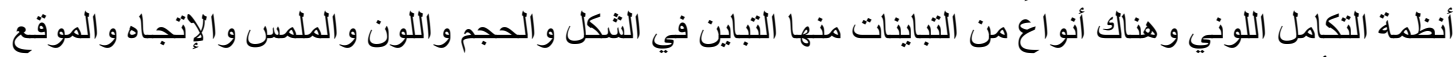

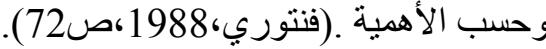

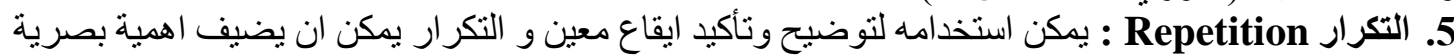

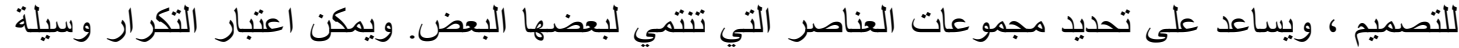

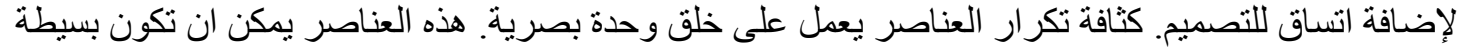

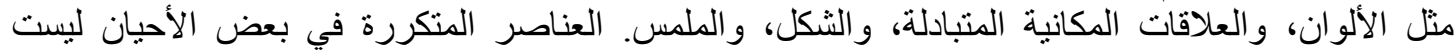
منطابقة ولكنها متشابهة ولكن تنقى علاقتهاو واضحة.

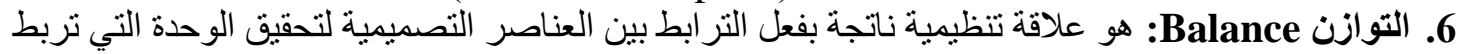

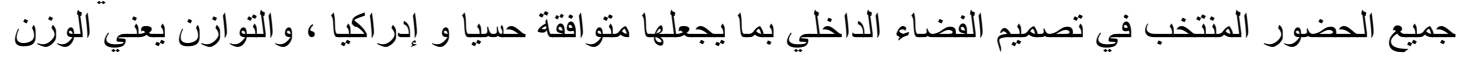

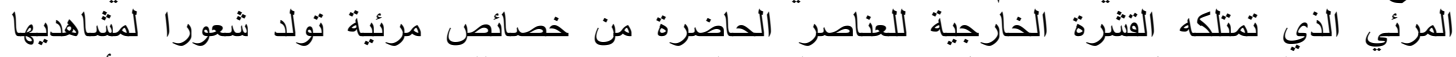

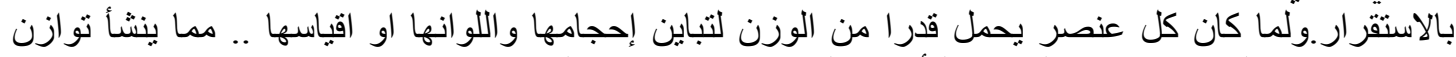

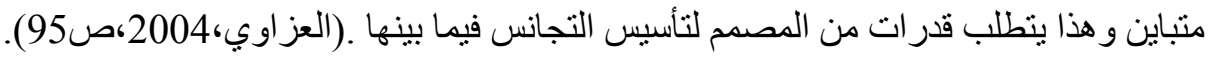




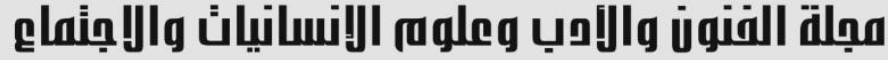

\author{
Journal of Arts, Literature, Humanities and Social Sciences \\ www.jalhss.com
}

Volume (52) May 2020

العدد (52) مايو 2020

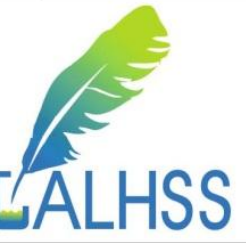

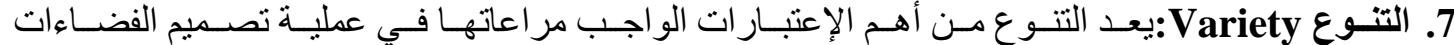

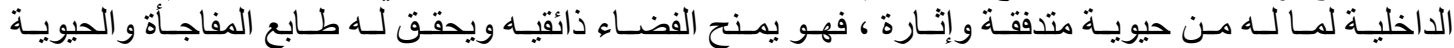

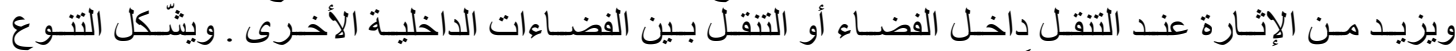

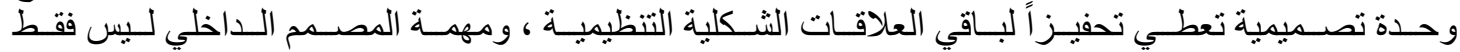

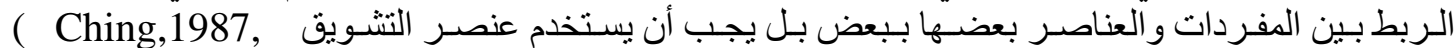

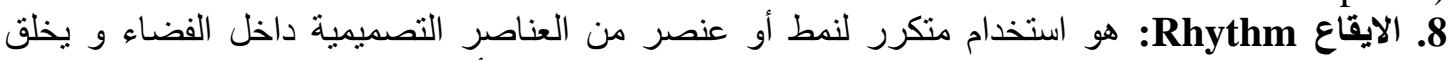

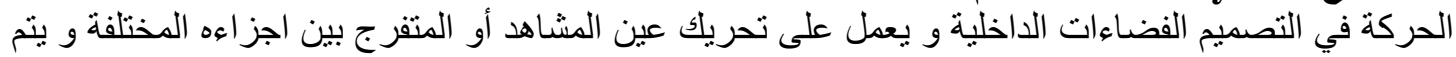

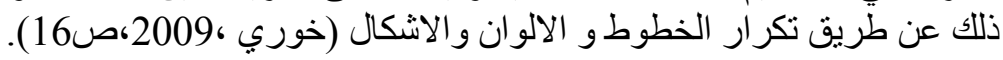

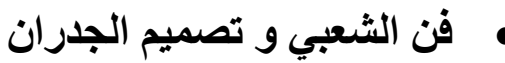

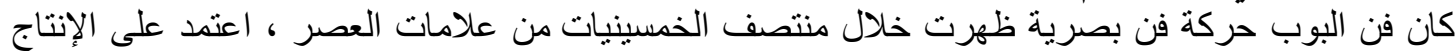

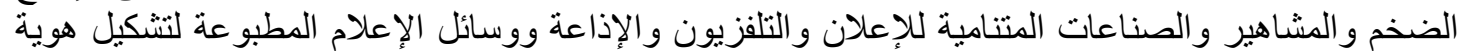

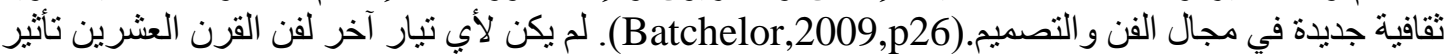

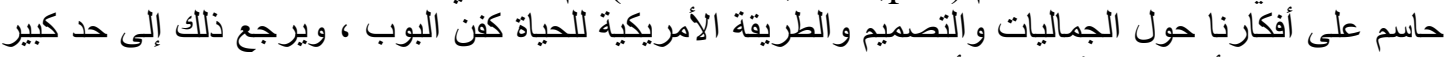

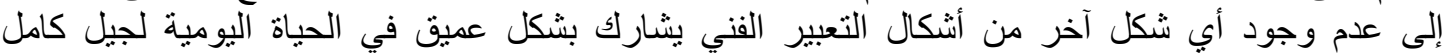

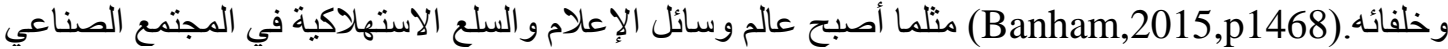

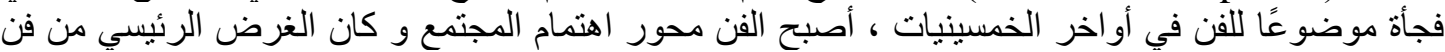

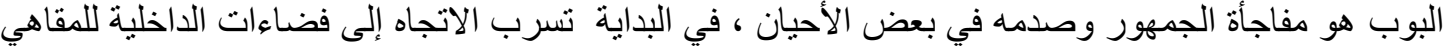

و المطاعم العصرية ، و عندها إلى المباني و الفضاءات السكنية. (Capitanucci,2014,p.205).

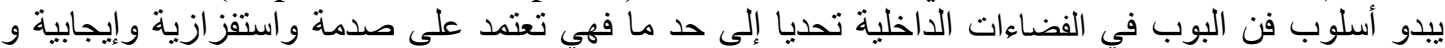

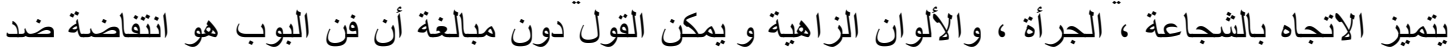

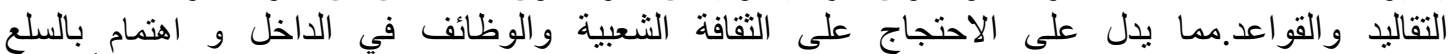

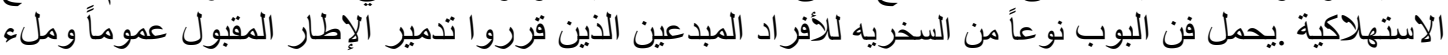

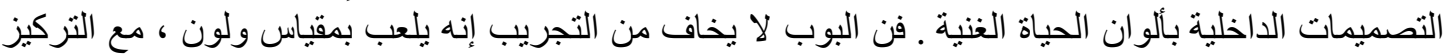

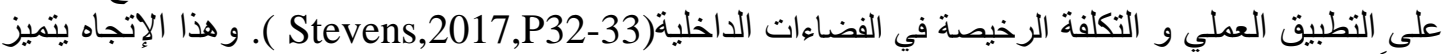

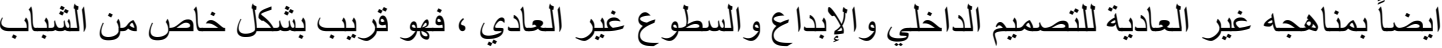

الذين هم على استعداد للعيش في حركة دائمة. (Massey,2001,P45)

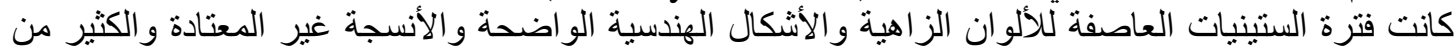

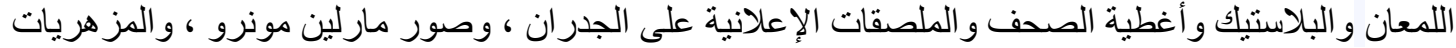

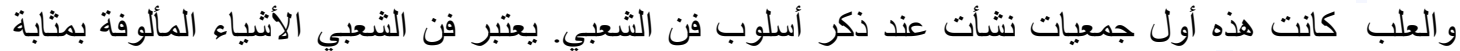

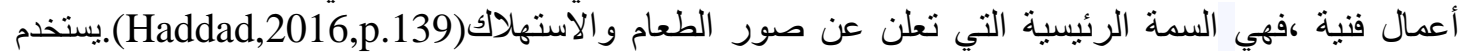

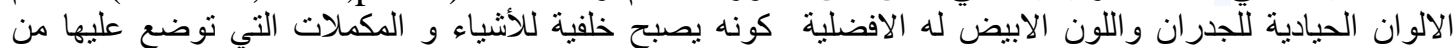

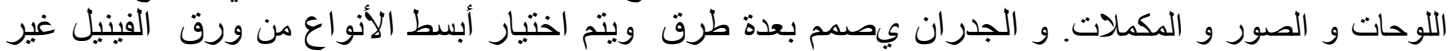

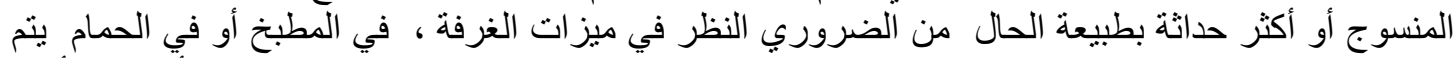

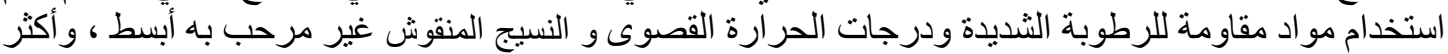

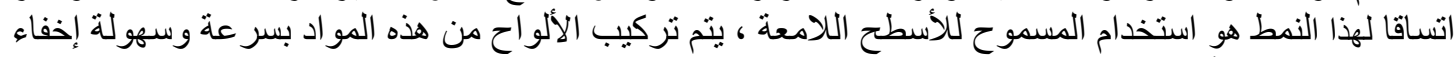

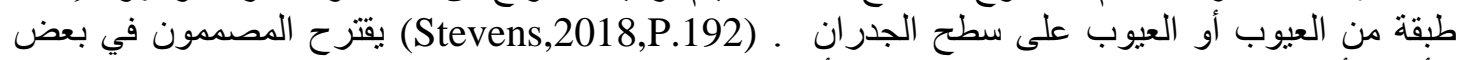

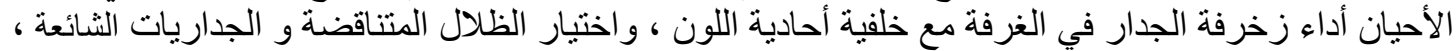

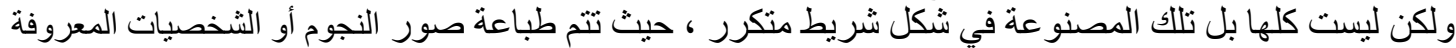

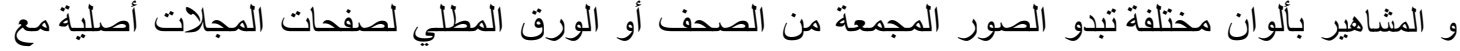

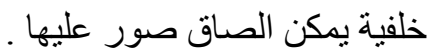




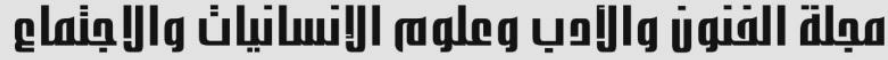

Journal of Arts, Literature, Humanities and Social Sciences www.jalhss.com

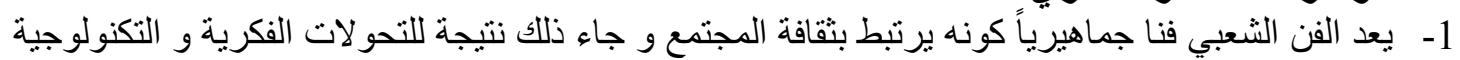

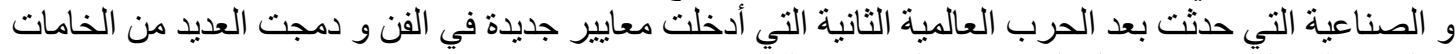

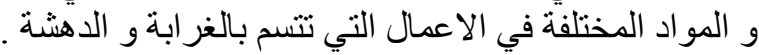

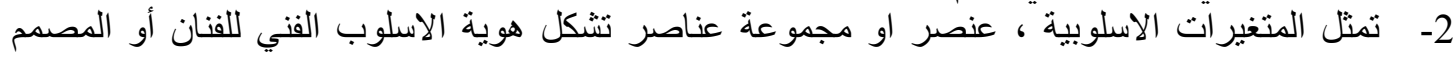

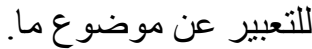
3- يؤسس الفن الثُبي الجمال وفق أطروحته الفكرية ، التي تجاوزت تجارب المدارس الحديثة ليكون البديل

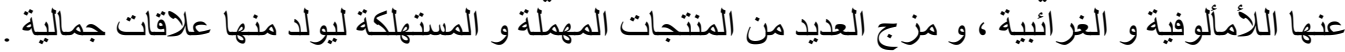

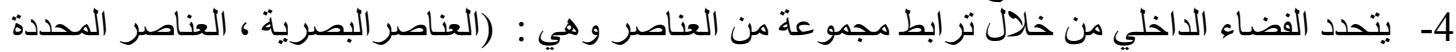
، العناصر الانتقالية ، العناصر التأثنثية ). 5- هناك علاقات تكوينية بين عناصر الفضاء التو و التي يتحدد بـ ( الوحدة ،السبادة ، التو افق ، التضاد ، التكرار،

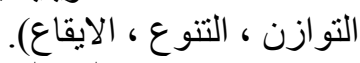

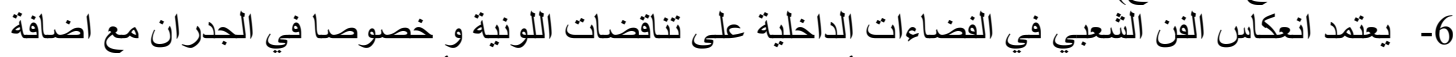

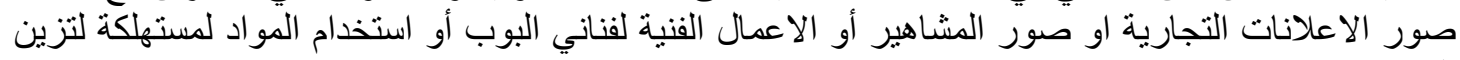

\section{الفصل الثالث \\ منهجية البحث البثم}

أولاً منهجية البحث : اعتمدت الباحثة المنهج الوصفي التحيليلي للوصول الى هدف البحث الحالي . ثانياً :مجتمع البحث : شمل مجتمع البحث على الجدران في الفضاءات الداخلية لمنازل التي تم تشيدها في فترة

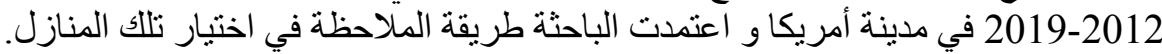

ثالثاً عينة البحث : تم اختيار العينة بطريقة قصدية من بين مجتمع البحث التي يبلغ عددها (15) منزل و و تكونت

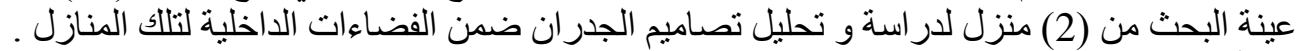

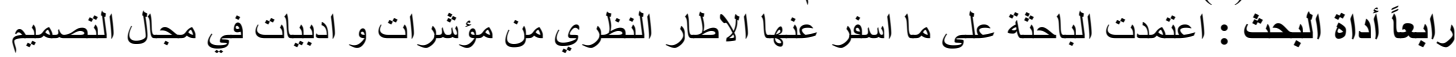

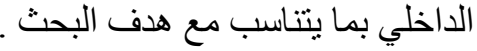

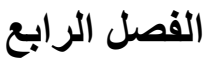

تعليل العينة

عينة (1) : فضاء داخلي خاص / منزل في بيفرلي هيلز / كاليفورنيا

\begin{tabular}{|c|c|c|c|c|c|}
\hline الدولة & سنتة & المساحة & المصمم & نوع الفضاء و وظيفته & ت \\
\hline الو لايات المريكية & 2012 & مربع 12000 قدم & $\begin{array}{c}\text { Martyn Lawrence } \\
\text { Bullard }\end{array}$ & سكني -غرفة الطعام & -1 \\
\hline
\end{tabular}




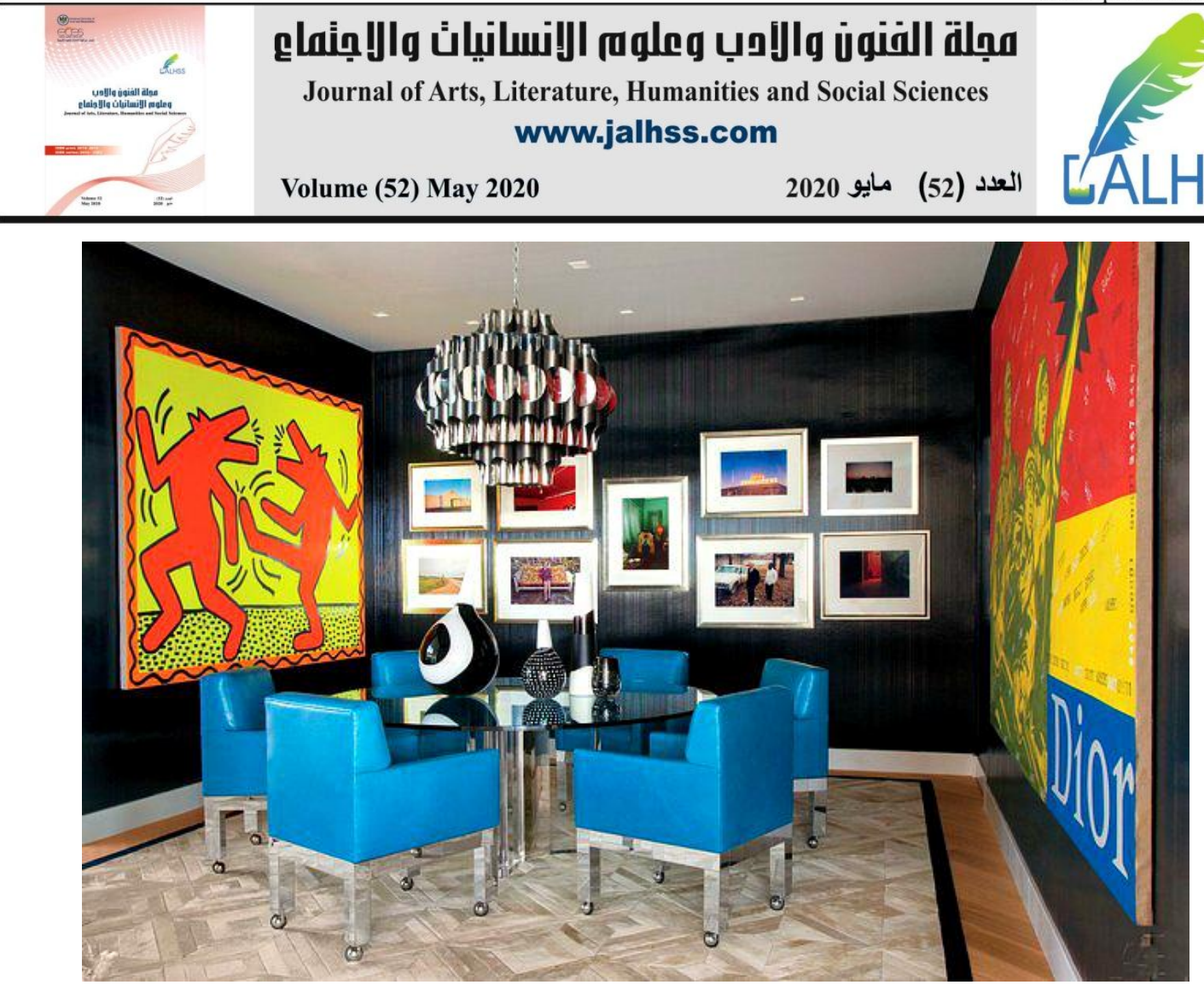

https://www.architecturaldigest.com/gallery/elton-john-david-furnish-los-angeles-homeslideshow

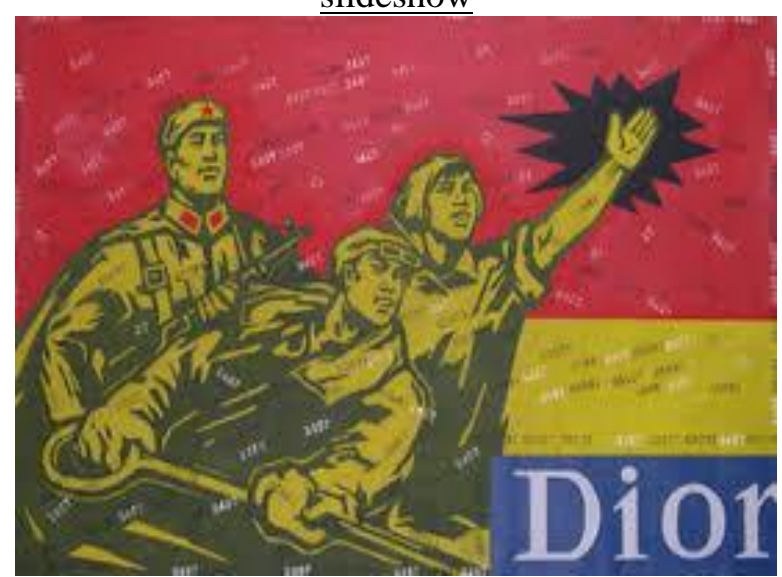

عمل الفنان وانغ جو انغيي (Wang Guangyi) المعلق على الجانب الايمن من الجدار

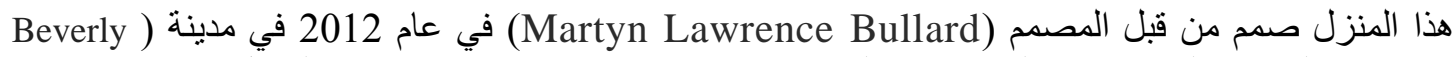

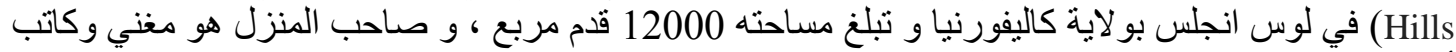

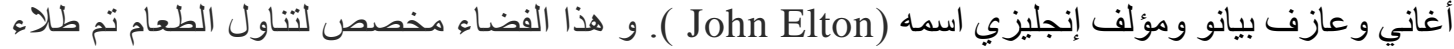

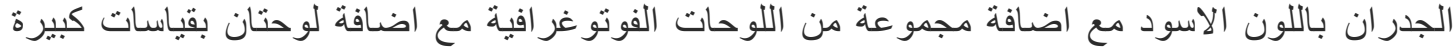

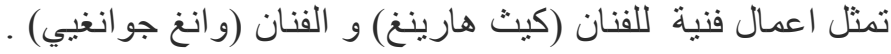




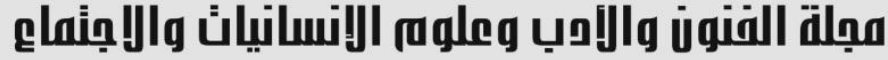

Journal of Arts, Literature, Humanities and Social Sciences
www.jalhss.com

ثانيا : تحليل العينة

اتسم هذا الفضاء بوجود الكثير من الصور و الاعمال الفنية بمقاسات مختلفة ، استخدم اللون الاسود كخلفية

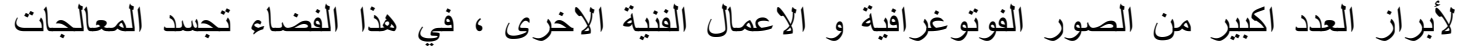

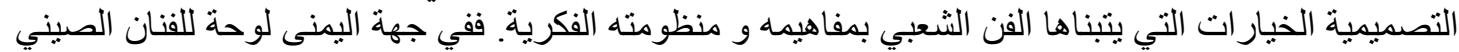

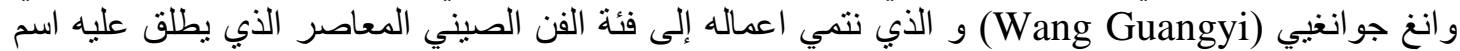

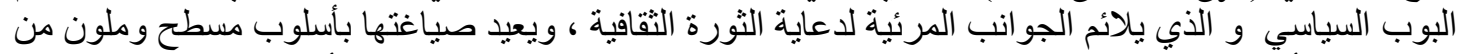

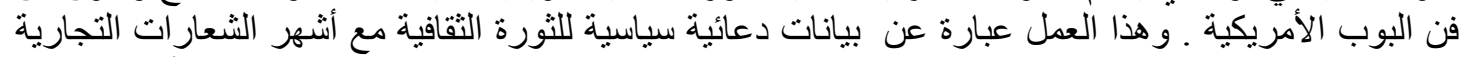

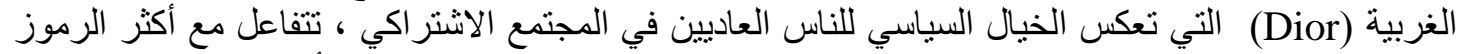

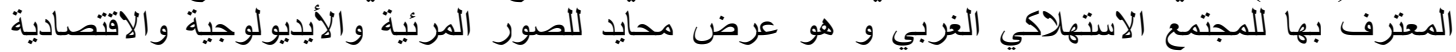

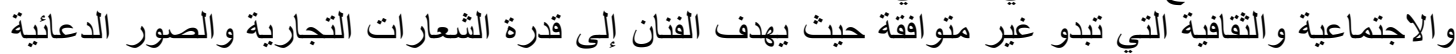

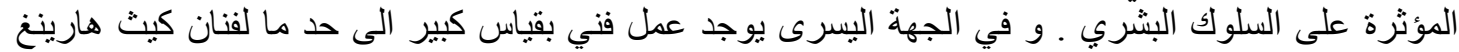
(Keith Haring)

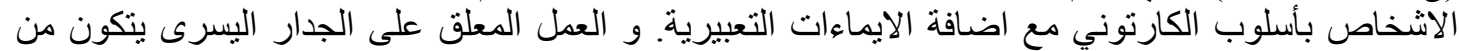

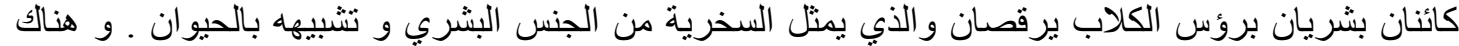

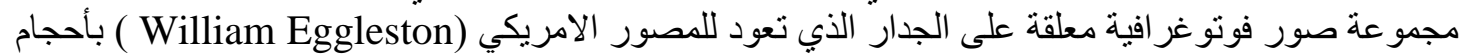

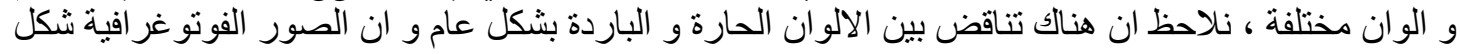

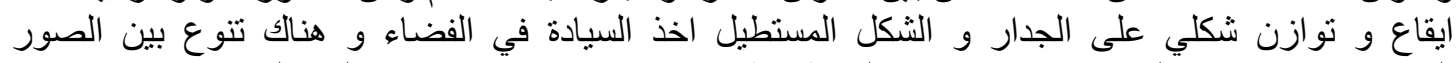

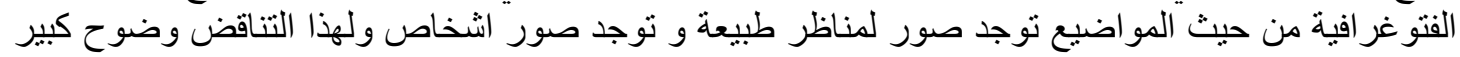

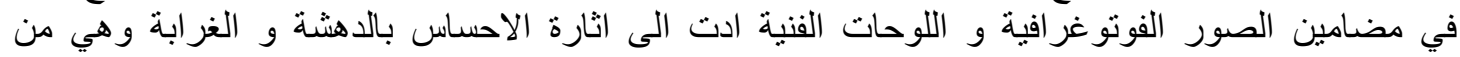
خصوصيات الفن الثعبي و فنون مابعد الحداثة.

عينة (2) : فضاء داخلي خاص / منزل في رويال اوك / الولايات المتحدة الامريكية

\begin{tabular}{|c|c|c|c|c|c|}
\hline الدولة الدولة & التفيذة & المساحة & المصمم & نوع الفضتاء و & ت \\
\hline الو لايات المتحدة الامريكية & 2019 & مربع 2000 قدم & Judy and John Davids & سكني- غرفة الطعام & -1 \\
\hline
\end{tabular}




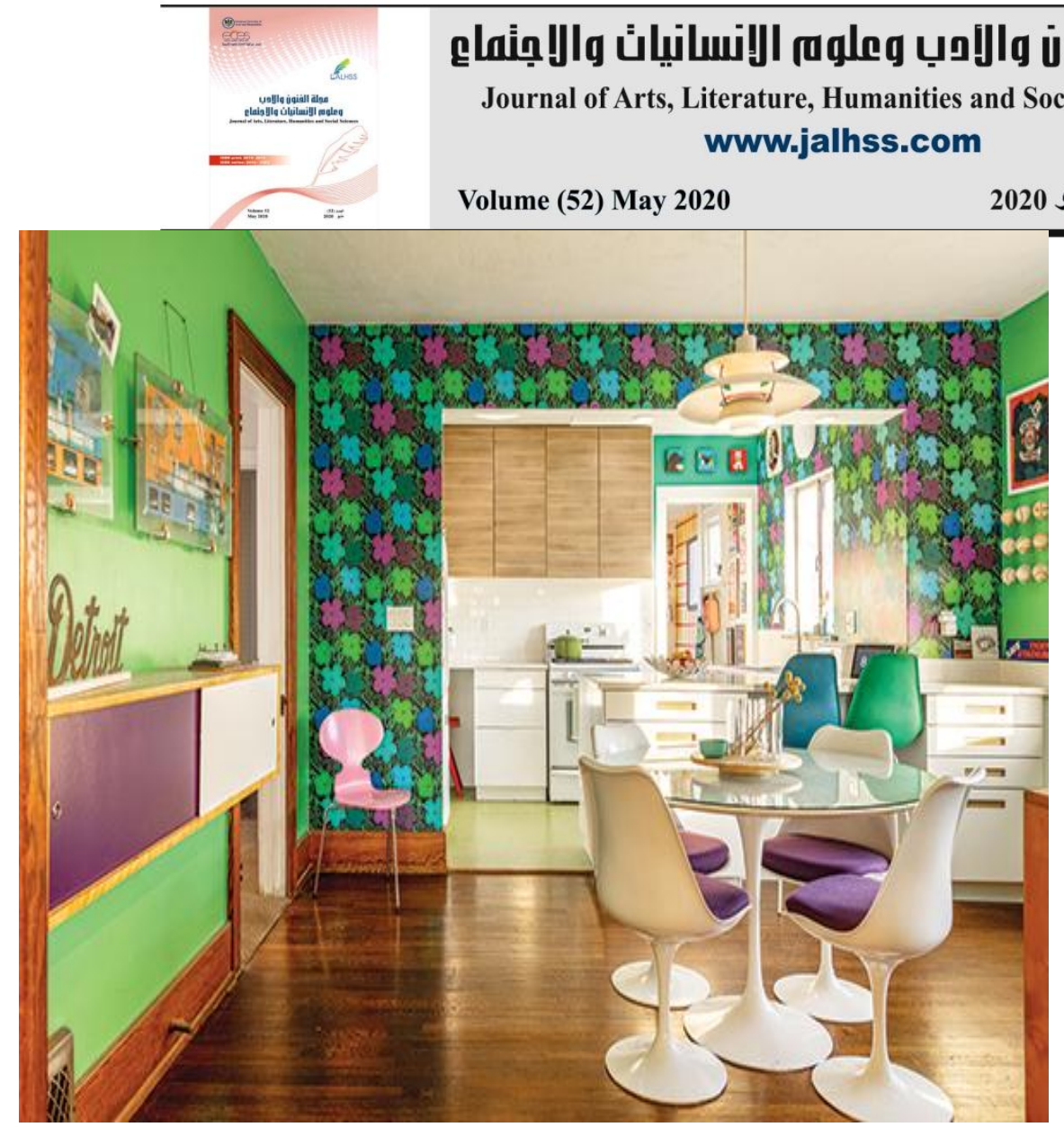

https://seenthemagazine.com/royal-oaks-pop-art-palace/

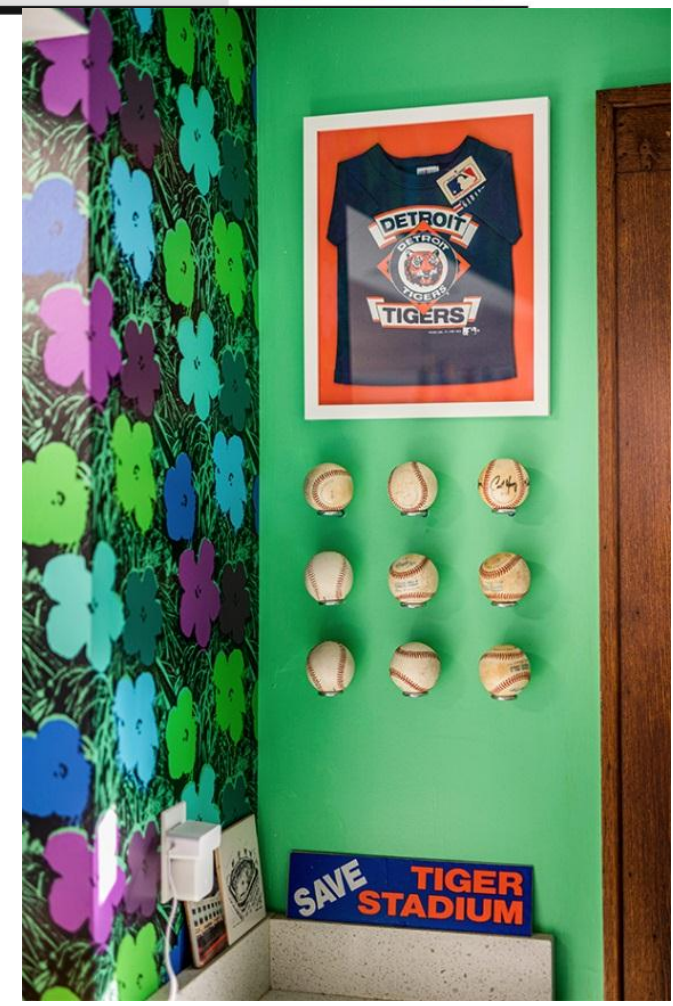

أولاً: وصف العينة

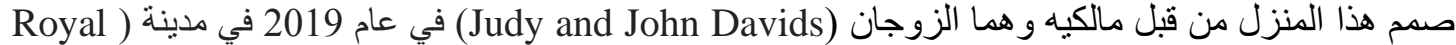

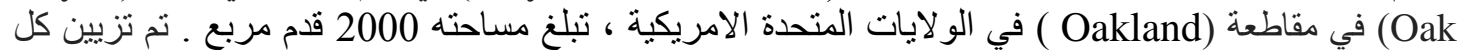

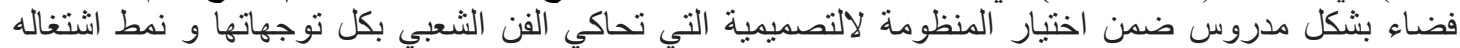

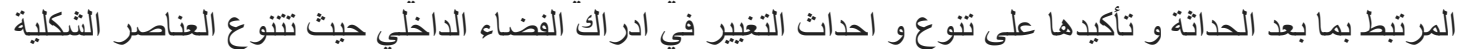

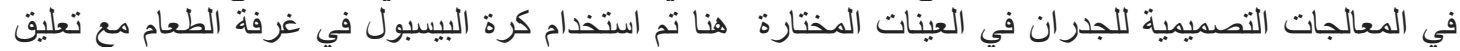

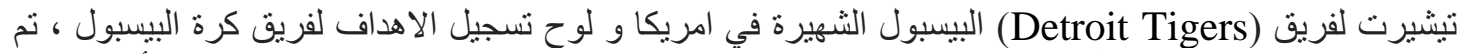

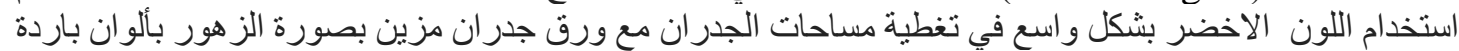

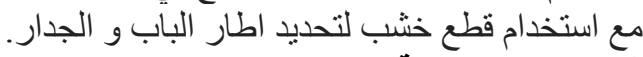
ثانيا : تحليل العينة

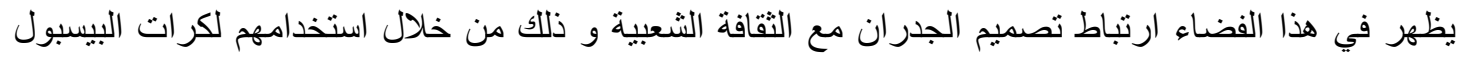

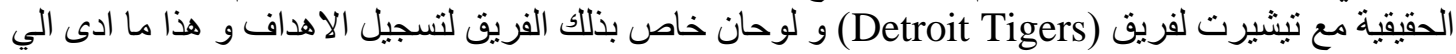

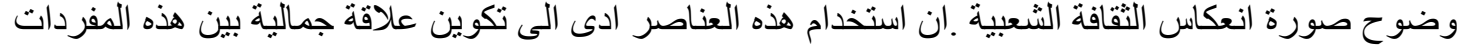

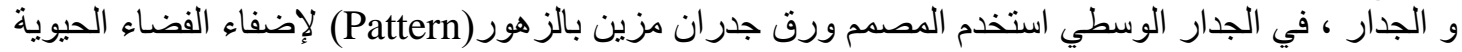

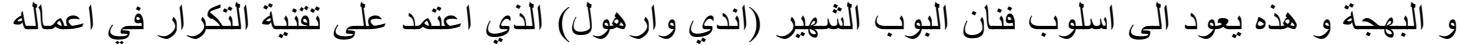

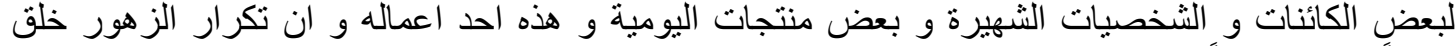

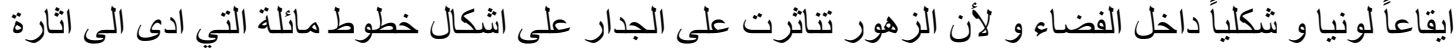

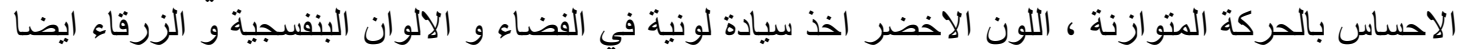

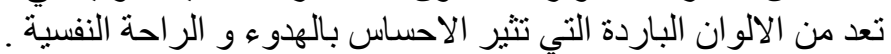




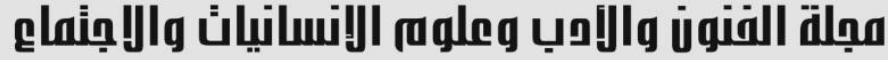

1. التثائج ج انعكاسات و اضحة للفن الشعبي على الجدران في الفضاءات السكنية و خاصة فضاء المخصص لتناول

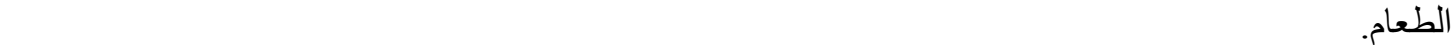
2. من السمات البارزة لإنعكاس الفن الثعبي في الفضاءات الداخلية و خصوصا على الجدران هي اضافة الأعمال الفنية لفناني (Pop Art). 3. عد التكر ار و التنوع في الاشكال و الالو ان من الاستر اتيجيات المهمة لأنعكاس الفن الثعبي على الجدران.

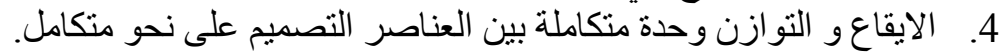

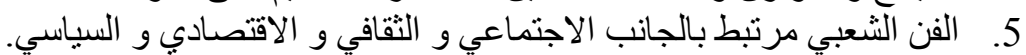

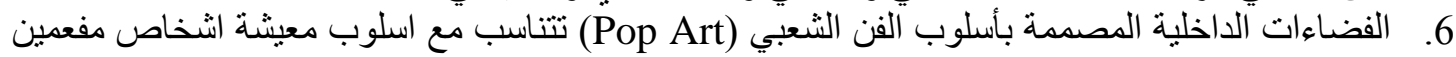
بالحركة و النشاط و الحيوية.

(1)الفن الفلكلوري: مصطلح انجليزي استخدمه لأول مرة عالم الأثريات الانجليزي سيرجون وليم تومز في عام 1846 وقدا

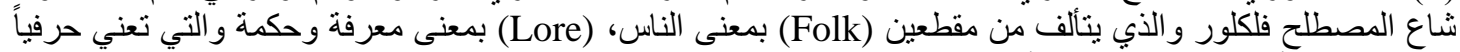

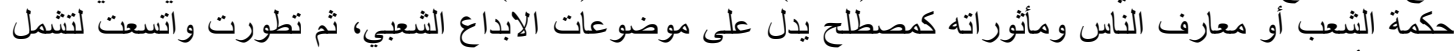

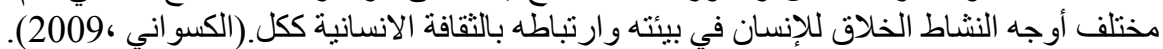

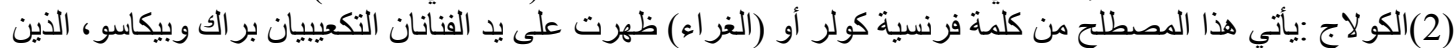

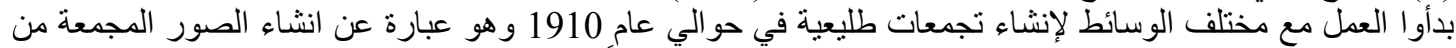

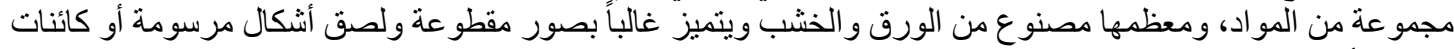
ثلاثية الأبعاد، و هذا مكن الفنانين من تجميع الصورة ومن من مكونات مختلفة بشكل حرفي. (crane,2014,p10).

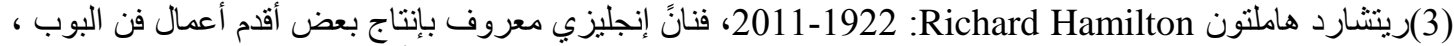

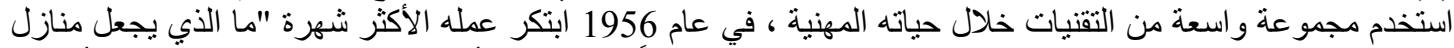

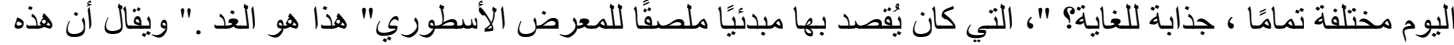

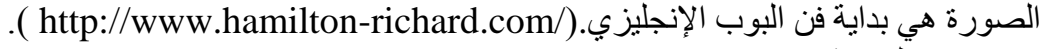

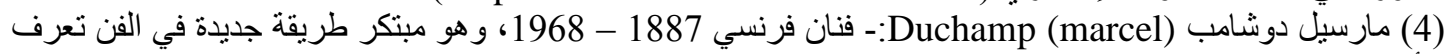

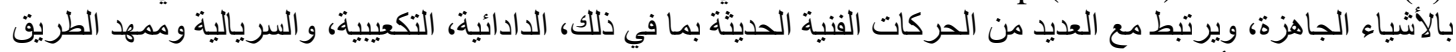

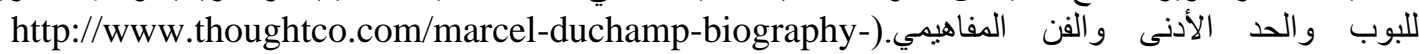
(4173366

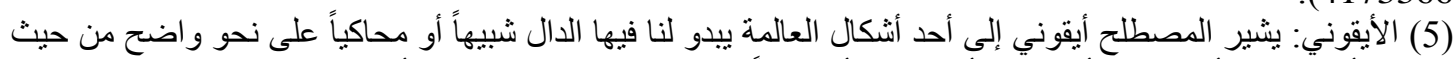

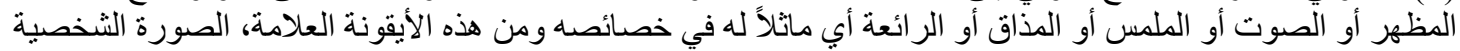

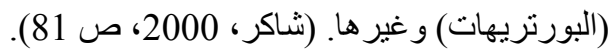




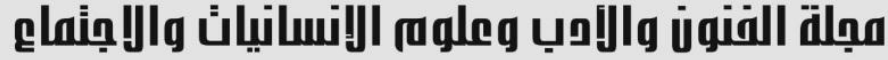

Journal of Arts, Literature, Humanities and Social Sciences
www.jalhss.com
$=\quad$ Volume (52) May $2020 \quad 2020$ مايو

المصادر العربية

1- ارنست ، فيشر، 1973 ، الاشتتراكبة و الفن ، ت ـ ـ اسعد حليم ، بيروت، دار القلم .

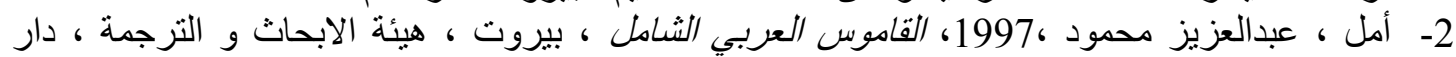

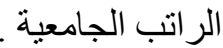
3- أمهز ،محمود، 1981، 1981/لفن التشكيلي المعاصر ، بيروت، لبنان ، دار المنلث للتصميم و الطباعة.

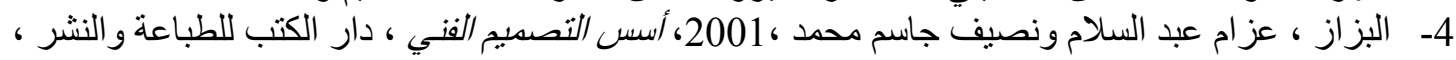

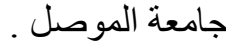

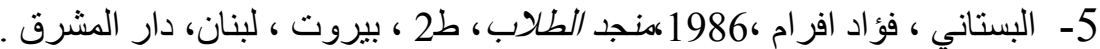

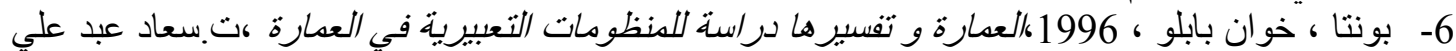
كبغداد ، دار الثؤون الثقافية العامة.

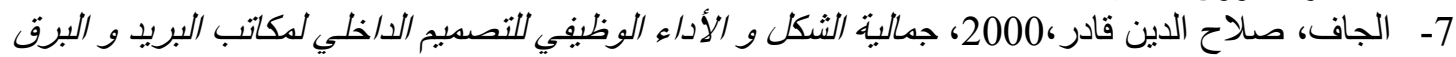

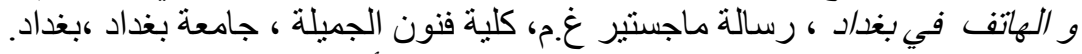

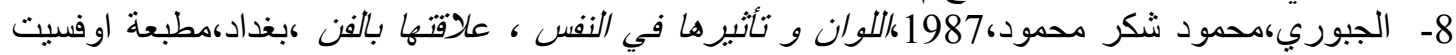
9- جيمنيز، مارك، 2012٪الجمالية الدعاصرة الاتجاهات و الرهانات، ت ت.كمال بومنير، الرباط، دار الأمان.

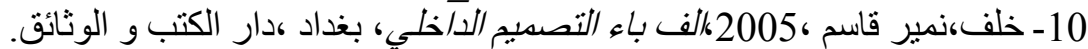

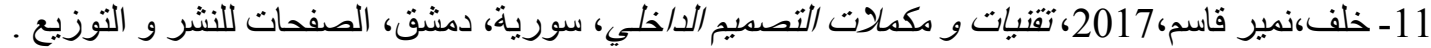

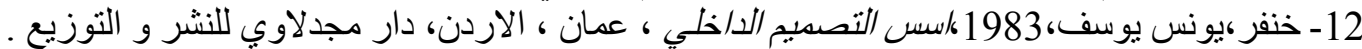

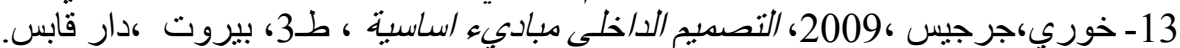

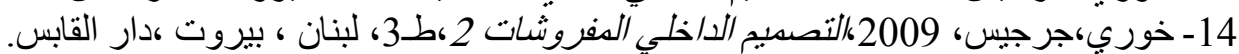

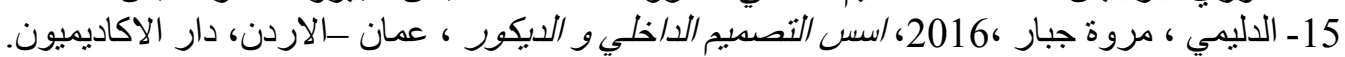

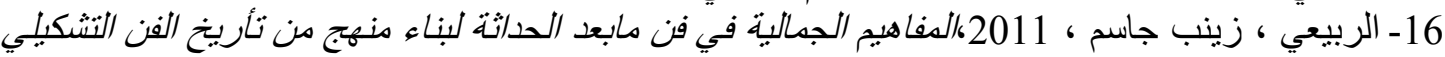

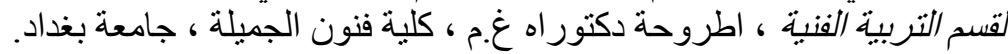

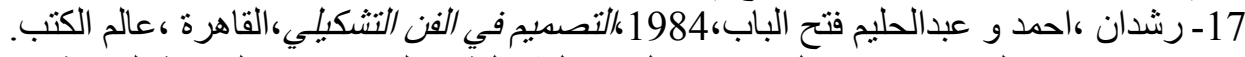

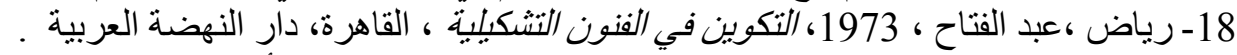

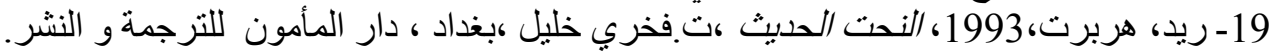

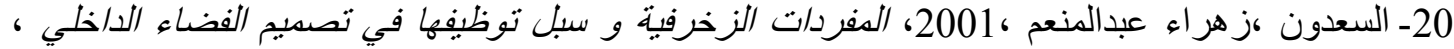
رسالة ماجستير غ.ع، جامعة بغداد،كلية فنون الجميلة ، قسم التصميج. 21- سكوت ، روبرت جيلام ،2015، اسس التصمبيم،ت.محمد محمد يوسف ،طل2، فالقاهرة، دار النهضة مصر ل ل الطبع و النشر.

22- سمث، ادو ارد لوسي، الحركات الفنبة بعد الحرب العالمبة الثانبة ،ت.فخري خليل، دار الثؤون الثقافية العامة

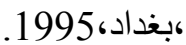

23- شاكر ، عبدالحمبد،2000، معجم المصطلحات الاساسية في علم العلامات (السيهوطيقا) ، اكاديمية الفنون ،

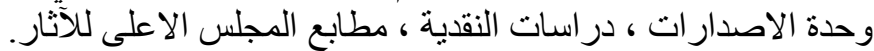

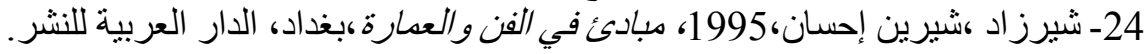

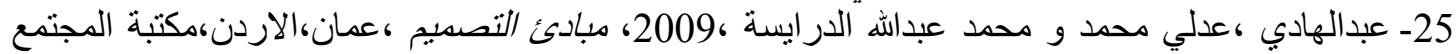

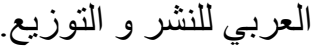

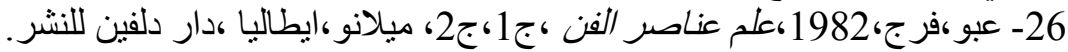

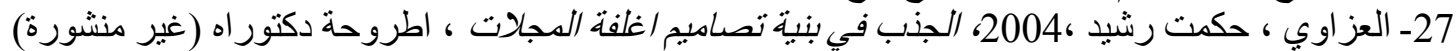

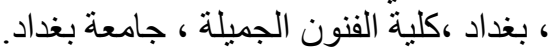

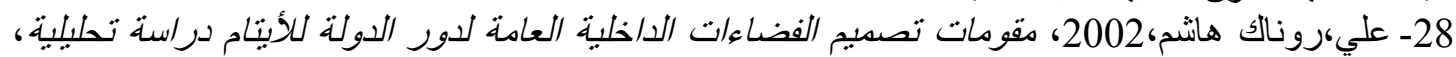

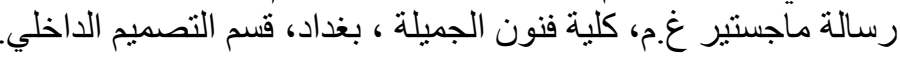

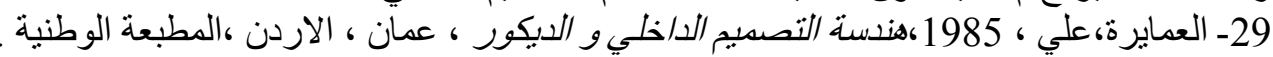

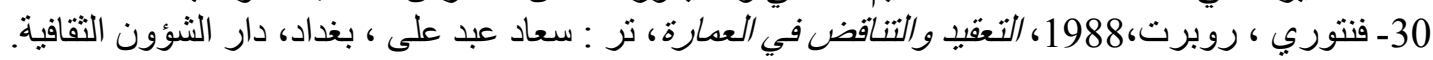




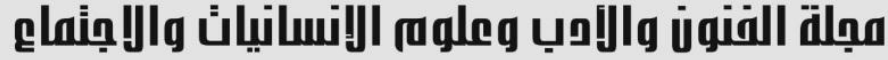

Journal of Arts, Literature, Humanities and Social Sciences www.jalhss.com

31- الكسو اني ، جهاد ،2009، حماية فولكلور الوطني ، مقال منشور على شبكة الانترنت، كلية الحقوق ، جامعة

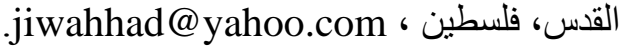

32- اللوس، بان إدوار، 2000، جلئلية العلاقة بين التصديم الداخلي والأعمال الفنبة التشكيلبة المعاصرة، رسالة

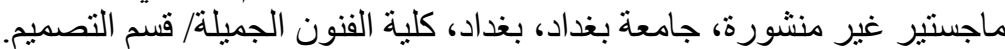

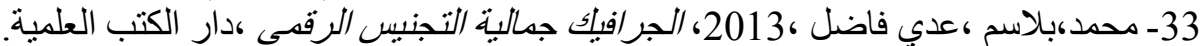

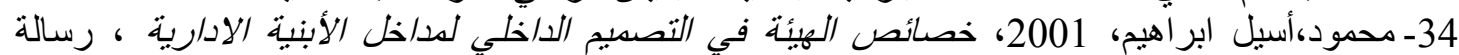

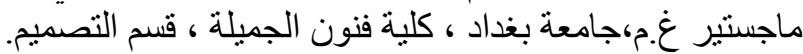

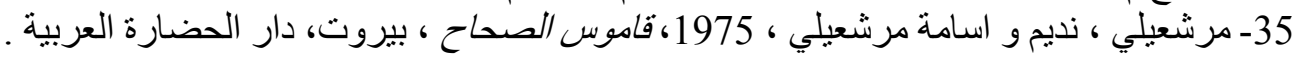

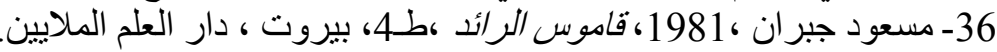

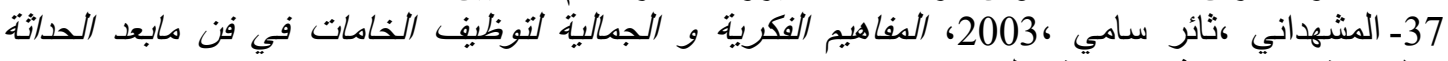

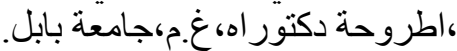

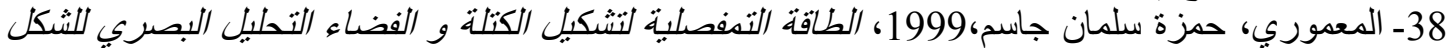

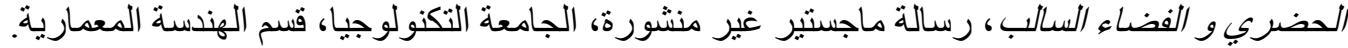

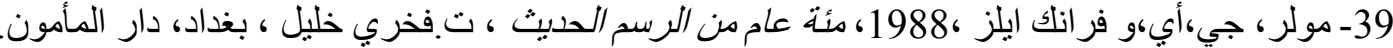

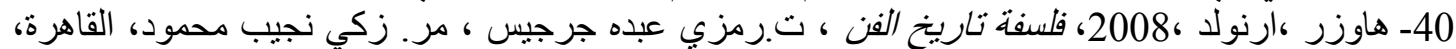

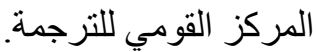

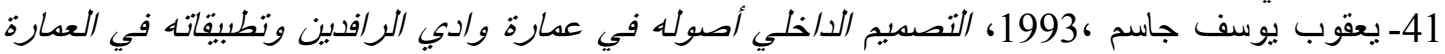
العباسية في سامراء ، رسالة ماجستير غ.غم، جامعة بغداد ، كلية الهندسة ، القسم المعماري. 


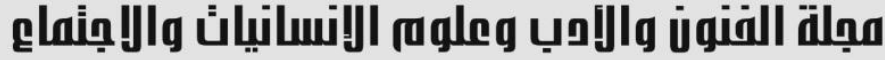 \\ Journal of Arts, Literature, Humanities and Social Sciences \\ www.jalhss.com \\ Volume (52) May 2020 \\ العدد (52) مايو 2020}

\section{References}

1- Abbou, Faraj, 1982, The Elements of Art, Part 1, Part 2, Milan, Italy, Dolphin Publishing.

2- Abdel-Hadi, Adly Muhammad and Muhammad Abdullah Al-Daraiseh, 2009, Design Principles, Amman, Jordan, Arab Society Library for Publishing and Distribution.

3- Al-Azzawi, Hikmat Rashid, 2004, Attracting the structure of magazine cover designs, PhD thesis (unpublished), Baghdad, College of Fine Arts, University of Baghdad.

4- Al-Bazzaz, Azzam Abdul Salam and Nassif Jassem Muhammad, 2001, Foundations of Artistic Design, Dar Al-Kutub for Printing and Publishing, University of Mosul.

5- Al-Bustani, Fouad Ephrem, 1986, Upholstered Students, 2nd floor, Beirut, Lebanon, Dar Al-Mashreq.

6- Al-Dulaimi, Marwa Jabbar, 2016, Foundations of Interior Design and Decoration, Amman-Jordan, Academics House.

7- Alexander ,Mary Jean, 1978, Designing Interior Environment, USA, Harcot Brace Javano Vich, Inc.

8- Ali, Ronak Hashim, 2002, Elements of Design of Public Interior Spaces for the State Orphans Role, Analytical Study, MA Thesis, M.G., College of Fine Arts, Baghdad, Department of Interior Design.

9- Al-Jaf, Salah Al-Din Qadir, 2000, Aesthetic appearance and functionality of interior design of post offices, telegraphs and telephones in Baghdad, MA, M.G., College of Fine Arts, University of Baghdad, Baghdad.

10- Al-Jubouri, Mahmoud Shukr Mahmoud, 1987, Color and its influence on the soul, its relationship to art, Baghdad, Offset Maj. Gen.

11-Al-Kiswani, Jihad, 2009, Protection of National Folklore, published article on the Internet, Faculty of Law, Al-Quds University, Palestine, jiwahhad@yahoo.com.

12- Al-Maamouri, Hamzah Salman Jasim, 1999, The Articulated Energy of Mass and Space Formation. Visual Analysis of Urban Form and Negative Space, Unpublished Master Thesis, University of Technology, Department of Architecture.

13- Al-Mashhadani, Thaer Sami, 2003, intellectual and aesthetic concepts for the use of raw materials in postmodern art, $\mathrm{PhD}$ thesis, G.M., University of Babylon.

14- Al-Rubaie, Zainab Jassim, 2011, Aesthetic Concepts in Postmodern Art to Build an Approach from the History of Plastic Art to the Department of Art Education, Ph.D. Thesis, College of Fine Arts, University of Baghdad.

15- Al-Saadoun, Zahraa Abdel-Moneim, 2001, decorative vocabulary and ways to employ it in interior space design, MA thesis, G.M., University of Baghdad, College of Fine Arts, Department of Design.

16- Amal, Abdulaziz Mahmoud, 1997, The Comprehensive Arabic Dictionary, Beirut, Research and Translation Authority, University Salary House. 


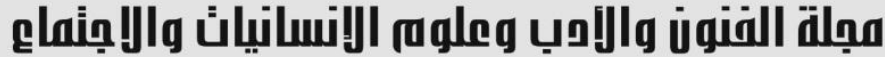

Journal of Arts, Literature, Humanities and Social Sciences

www.jalhss.com

Volume (52) May 2020

العدد (52) مايو 2020

17- Amayreh, Ali, 1985, Interior Design and Decoration Engineering, Amman, Jordan, National Printing Press.

18- Amhaz, Mahmoud, 1981, Contemporary Art, Beirut, Lebanon, Triangle House for Design and Printing.

19- Ball,Victoria Klass, 1980, Architecture and Interior design, John willy and sors LTUSA.

20- Banham,Joanna, , 2015,Encyclopedia of Interior Design, London , Chicago ,

Fitzroy Dearborn Publishers.

21- Batchelor,bob, ,2009,Amrican pop popular culture decade by decade,volume 1 1900-1929, London, greenwood press.

22-Capitanucci, Maria Vittoria , 2014,The Big Book of Interior Design, Italy, Ore Cultural Srl,Milan.

23-Ching F.D, 1987, Architecture From Space and Order, ,London, Van Nastrand Rein hold Company.

24- Compton, Michael, 1970, Pop Art Hamlyn, London.

25-Crane, Rona, 2014,Collage in Twentieth-Century Art, Literacture and Culture, England, Burlington,VT, Ash gate Fern ham , Surrey,.

26- Ernst, Fischer, 1973, Socialism and Art, T. Asaad Halim, Beirut, Dar Al-Qalam.

27- Flynn,John E and Sigil , Arthur W.and Stuffy , Gary,R, 1988, Architectural Interior System, Lighting A coustics Air Conditioning, New York, Van No Stand Reinhold.

28- Friedman,Arnold and Others,1979, Interior Design :A introduction to Architectural Interior, American Elsevier pub,Inc,

29- Gary,Gordon,IALD,IES James L.Nuckolls,ALD， 1995,Interior Lighting For Designers, $3^{\text {rd }}$ Edition, New York, John Wiley \& Sons, Inc.

30- Graves, Maitland, 1951,The Art of Color and Design, 2nd Ed., McGraw-Hill Book company, Inc.

31-Haddad, Elie G,6 David Rifkind, 2016, A Critical History of Contemporary Architecture: 1960-2010, NewYork,USA ,Ash gate puplishing.

32- Hauser, Arnold, 2008, The Philosophy of Art History, T. Ramsey Abdo Gerges,

M. Zaki Naguib Mahmoud, Cairo, the National Center for Translation.

33- http://www.thoughtco.com/marcel-duchamp-biography-4173366

34- https://seenthemagazine.com/royal-oaks-pop-art-palace/

35- https://www.architecturaldigest.com/gallery/elton-john-david-furnish-los-angeleshome-slideshow.

36- Jimenez, Marc, 2012, Contemporary Aesthetic - Trends and Bets, Kamal Boumner, Rabat, Dar Al-Aman.

37- Julian Bicknell , Liz Mc Question , 1977, Inside Design for Need - The Social contribution of Design, London, Printed and Bound in Great Britain by Butler, Tanner Ltd.

38- Khalaf, Nameer Qasem, 2017, Interior Design Techniques and Supplements, Syria, Damascus, Pages for publication and distribution.

39- Khalaf, Nameer Qassem, 2005, A.B.B. Interior Design, Baghdad, House of Books and Documents. 


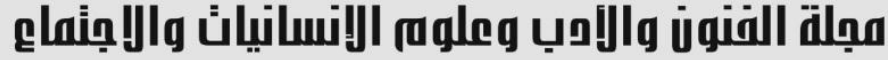 \\ Journal of Arts, Literature, Humanities and Social Sciences \\ www.jalhss.com \\ Volume (52) May 2020 \\ العدد (52) مايو 2020}

40- Khanfar, Younis Yousef, 1983, Foundations of Interior Design, Amman, Jordan, Majdalawi Publishing and Distribution House.

41- Khoury, Zarzis, 2009, Interior Design Furniture 2, T3, Lebanon, Beirut, Dar AlGabes.

42- Khoury, Zarzis, 2009, Interior design, basic principles, 3rd floor, Beirut, Dar Gabes.

43- Kilmer,Rosemary, ASID, W. Otie Kilmer, AIA,2014, Designing interiors, $2^{\text {nd }}$ edition, New Jersey, Canada, John Wiley \& Sons.

44- Krier ,Rob, 1988,Elements Of Architecture, Interior and the Typology of Interior Space ,Mc.Craw Hill Book Company .

45- Kries,mateo \& Schwartz-clauss,matgias, 2013,pop art design ,vitra design museum,English edition,.

46- Lawus, Ban Edwar, 2000, Controversial Relationship between Interior Design and Contemporary Fine Art, Unpublished Master Thesis, University of Baghdad, Baghdad, College of Fine Arts / Design Department.

47- Mahmoud, Aseel Ibrahim, 2001, Characteristics of the Commission in Interior Design for Entrances to Administrative Buildings, MA Thesis, M.G., University of Baghdad, College of Fine Arts, Department of Design.

48- Malnar, Joy Minico and Vodvarka, Frank , 1992,The Interior Dimension, Theoretical Approach to Enclosed Space, New York, Van Nostrand Reinhold.

49- Marshaili, Nadim and Osama Morshaili, 1975, Al-Sahah Dictionary, Beirut, Dar of Arab Civilization.

50- Masoud Jubran, 1981, Al-Raed Dictionary, 4th floor, Beirut, Dar Al-Alam, Millions.

51- Massey, Anne ,2001,Interior Design of the 20th Century, London, United Kingdom, Thames.

52- Miess,Pierre Van, 1990, Elements Of Architecture ,Form-Form to Place, New York, E and FN Spon .

53- Muhammad, Balsam, Uday Fadel, 2013, Graphic Aesthetic Digital Digitalization, Scientific Books House.

54- Muller, G., E., and Frank Eles, 1988, Hundred Years of Modern Painting, T. Fakhri Khalil, Baghdad, Dar Al-Mamoun.

55- Nesbitt,Kat, 1996,The Orizing A new Agenda for Architecture AN ANTHOLOGY of Theory Architectural 1965-1995, New York ,Princeton Architectural press.

56- Osterwold,Tilman,1999,Pop Art, Cologne, Germany, Benedikt Taschen Verlag $\mathrm{GmbH}$.

57- Punta, Juan Pablo, 1996, Architecture and Its Interpretation A study of expressive systems in architecture, T. Suad Abdul Ali, Baghdad, House of General Cultural Affairs.

58- Rashdan, Ahmed and Abdel-Halim Open the door, 1984, design in the art, Cairo, the world of books.

59- Reid, Herbert, 1993, Modern Sculpture, T. Fakhri Khalil, Baghdad, Dar AlMamoun for Translation and Publishing. 


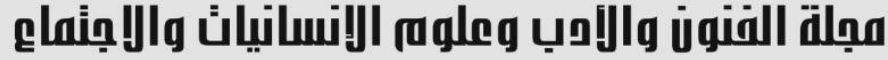 \\ Journal of Arts, Literature, Humanities and Social Sciences \\ www.jalhss.com \\ Volume (52) May 2020 \\ العدد (52) مايو 2020}

60- Richard, Hollis, 2005, Graphic Design A Concise History World of Art ,New York, Thames and Hudson.

61-Riyadh, Abdel-Fattah, 1973, Training in Plastic Arts, Cairo, Arab Renaissance House.

62-Scott, Robert Gillam, 2015, Foundations of Design, M. Mohamed Mohamed Youssef, 2nd Floor, Cairo, Dar Al-Nahda Egypt for Printing and Publishing.

63-Shaker, Abdul Hamid, 2000, Lexicon of Basic Terms in the Science of Marks (SimoTigma), Academy of Arts, Publications Unit, Critical Studies, Supreme Council of Antiquities Press.

64- Sherzad, Sherine Ehsan, 1995, Principles in Art and Architecture, Baghdad, Arab Publishing House.

65- Shines, Eric,2009, Pop Art, New York, USA ,Parkston International.

66- Smith, Edward Lucie, 1981, Pop Art in Concepts of modern Art, London, Thames and Hudson Ltd.

67- Smith, Edward Lucy, Art Movements after World War II, Fakhri Khalil, General Cultural Affairs House, Baghdad, 1995.

68-Stevens, Rebecca S ,Clara Macintyre,2018, Brief guide of modern styles in interior, ,VAST Publishing House.

69- Stevens, Rebecca S, Clara Macintyre , 2017,Features of the Style Pop Art in the Interior: Design and interior decoration, VAST Publishing House.

70- Stoksad,Marilyn,W.Cothren,Michael,Contirbutors,Frederick A.Asher _..[egal.] ,2011,Art History ,V2,4thed, Library Of Congress Cataloging -in Publication Data.

71- Venturi, Robert, 1988, Complexity and Contradiction in Architecture, see: Souad Abd Ali, Baghdad, House of Cultural Affairs.

72- Williason,Samuel.J\&Gummins.H, 1973, Light and Color in Natural Art, MC.Graw -Hill book Co.

73-www.Gartechome.com.

74- Yaqoub Yusuf Jasim, 1993, Interior Design, Its Origins in Wadi Al Rafidain Architecture and its Applications in Abbasid Architecture in Samarra, MA Thesis M.G., Baghdad University, College of Engineering, Architectural Department. 